\title{
Physical Nature of Chromatin in the Nucleus
}

\author{
Kazuhiro Maeshima, ${ }^{1,2}$ Shiori lida, ${ }^{1,2}$ and Sachiko Tamura ${ }^{1}$ \\ ${ }^{1}$ Genome Dynamics Laboratory, National Institute of Genetics, Mishima, Shizuoka 411-8540, Japan \\ ${ }^{2}$ Department of Genetics, School of Life Science, Sokendai (Graduate University for Advanced Studies), \\ Mishima, Shizuoka 411-8540, Japan \\ Correspondence: kmaeshim@nig.ac.jp
}

\begin{abstract}
Genomic information is encoded on long strands of DNA, which are folded into chromatin and stored in a tiny nucleus. Nuclear chromatin is a negatively charged polymer composed of DNA, histones, and various nonhistone proteins. Because of its highly charged nature, chromatin structure varies greatly depending on the surrounding environment (e.g., cations, molecular crowding, etc.). New technologies to capture chromatin in living cells have been developed over the past 10 years. Our view on chromatin organization has drastically shifted from a regular and static one to a more variable and dynamic one. Chromatin forms numerous compact dynamic domains that act as functional units of the genome in higher eukaryotic cells and locally appear liquid-like. By changing DNA accessibility, these domains can govern various functions. Based on new evidences from versatile genomics and advanced imaging studies, we discuss the physical nature of chromatin in the crowded nuclear environment and how it is regulated.
\end{abstract}

\section{DNA, GENOME, AND INFORMATION STORAGE IN THE NUCLEUS}

ow much information can be stored in the nucleus of a cell? Biological (or genetic) information is inscribed in deoxyribonucleic acid. DNA is a negatively charged double-helix polymer, composed of four bases (guanine, G; adenine, A; thymine, T; cytosine, $\mathrm{C}$ ), which are linked by a negatively charged phosphate backbone (Fig. 1A). A single human cell has $\sim 2 \mathrm{~m}$ of DNA $\left(0.33 \mathrm{~nm} \times 3 \times 10^{9} \mathrm{bp} \times 2\right.$ sets of chromosomes), which is $\sim 2 \times 10^{5}$-fold longer than the typical diameter of a nucleus $(\sim 10 \mu \mathrm{m})$ (Fig. 1B). Given that the human genome has $3 \times 10^{9}$ bp composed of four bases, there are $4^{\left(3 \times 10^{\wedge} 9\right)}$ combinations of information in it, which is equivalent to $2^{\left(6 \times 10^{\wedge} 9\right)}$, or $750 \mathrm{M}(0.75 \mathrm{G})$ bytes. This roughly corresponds to only a single compact disc (CD) ( 700 M bytes) and is much smaller than our current smartphones' memory storage.

However, the memory density of the human genome in the nucleus can be calculated as $\sim 7.5 \times 10^{14}$ bytes $/ \mathrm{mm}^{3}$, considering that the nuclear volume is roughly $1000 \mu \mathrm{m}^{3}$. This memory density is several orders of magnitude higher than a $\mathrm{CD}\left(5.2 \times 10^{4}\right.$ bytes $\left./ \mathrm{mm}^{3}\right)$, blu-ray disc (QL) $\left(9.4 \times 10^{6}\right.$ bytes $\left./ \mathrm{mm}^{3}\right)$, or even a flash memory $\left(16 \mathrm{~Gb}, 6.3 \times 10^{8}\right.$ bytes $\left./ \mathrm{mm}^{3}\right)$ (Church et al. 2012). Including possible chemical modifications on DNA and histones, such as methyl-

Editors: Ana Pombo, Martin W. Hetzer, and Tom Misteli

Additional Perspectives on The Nucleus available at www.cshperspectives.org

Copyright (C) 2021 Cold Spring Harbor Laboratory Press; all rights reserved; doi: 10.1101/cshperspect.a040675

Cite this article as Cold Spring Harb Perspect Biol 2021;13:a040675 
K. Maeshima et al.

A

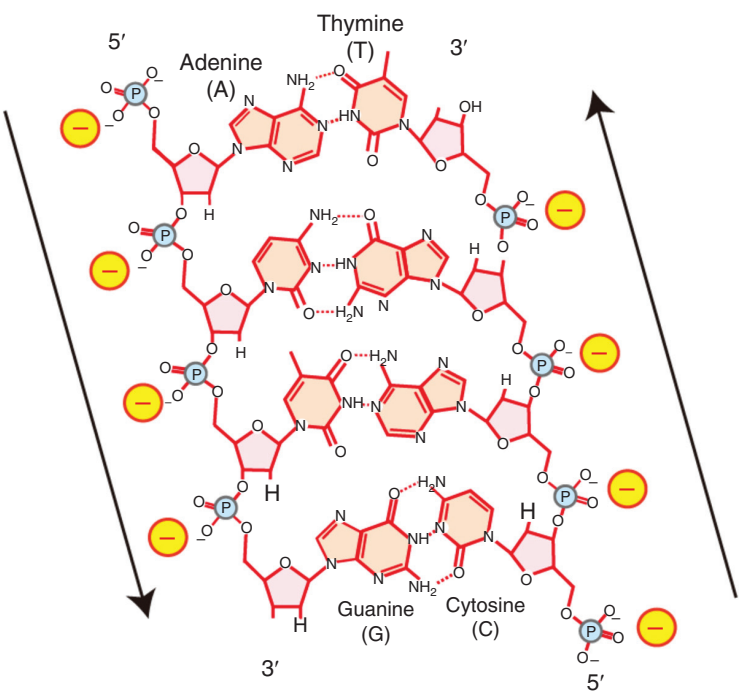

DNA (deoxyribonucleic acid)

B

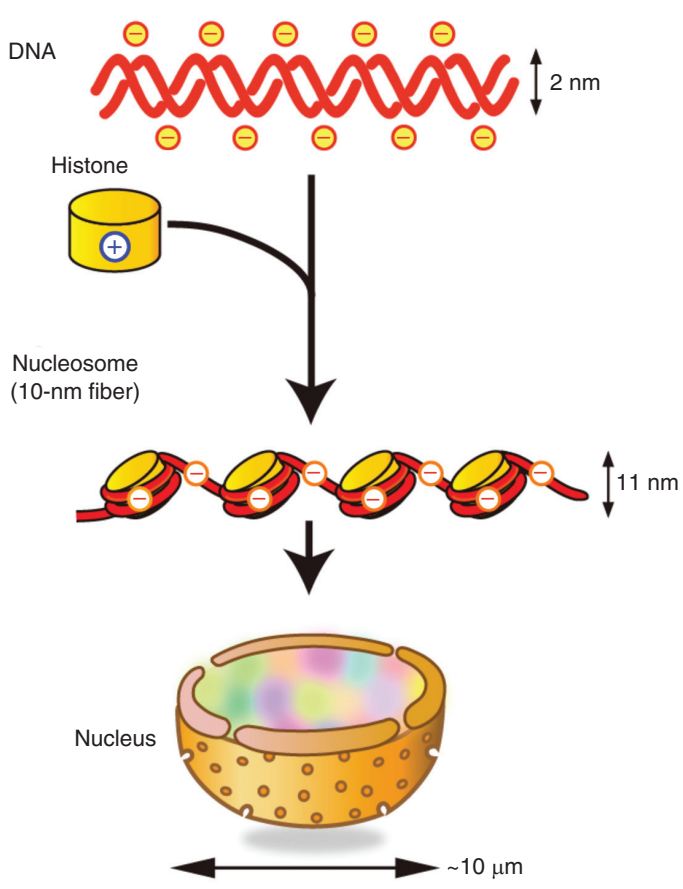

Figure 1. DNA, histones, and the nucleosome. (A) Schematic of the structure of deoxyribonucleic acid (DNA). DNA is a long double-helix polymer made from repeating units called nucleotides, that consists of four bases: adenine $(A)$, cytosine $(C)$, guanine $(G)$, and thymine $(T)$, which are attached to the sugar/phosphate. Adenine pairs with thymine and guanine pairs with cytosine by hydrogen bonds. The two strands of DNA run in opposite directions to each other in an antiparallel manner (shown by arrows). Phosphate backbones are negatively charged (marked with “-”). (Illustration and legend from Nozaki et al. 2018; reproduced with modifications, with permission, from the authors.) (B) Negatively charged DNA (top row) is wrapped around basic (or positive) core histone octamers (yellow on second row) to form 10-nm fiber, and it is further organized in a cell nucleus. Note that the fiber is still negatively charged. 
ation and acetylation, this calculation increased dramatically to encompass an enormous memory size and density. Reading of information requires energy and if one assumes that a $1 \mathrm{~Gb}$ flash memory needs roughly $\sim 1 \mathrm{~J}$ ( $1 \mathrm{~W}$ per $1 \mathrm{sec}$ ) of electric power and a similar level of energy was required in each cell of our body $\left(\sim 40 \times 10^{12}\right.$ cells; Bianconi et al. 2013$)$ to read its genetic information, the total energy required would be $\sim 4 \times 10^{13} \mathrm{~J}$, which is far greater than the total electric energy produced by all the nuclear power plants on earth (one plant can produce $\left.\sim 1 \times 10^{9} \mathrm{~J}\right)$. In other words, the nuclear genome works with amazing energy efficiency.

It is thus appropriate to call the nucleus a truly "amazing memory device" in terms of both information storage and readout. Although our above example used the human cell nucleus, this remarkable property is shared widely across all eukaryotic nuclei. To function correctly, genome DNA needs to be carefully and properly organized in the nucleus, where differences in DNA folding can bring about dramatic changes in information readout. In this article, we review and discuss how genomic DNA is organized and behaves in the nucleus.

\section{THE NUCLEOSOME}

The electric charge of its components is an essential part of understanding the organization of the genomic information in the nucleus. Negatively charged DNA is wrapped around a core histone octamer (Fig. 1B), which consists of four positively charged histone proteins $(\mathrm{H} 2 \mathrm{~A}, \mathrm{H} 2 \mathrm{~B}, \mathrm{H} 3$, and $\mathrm{H} 4$ ), and forms a nucleosome (Figs. $1 \mathrm{~B}$ and 2; Kornberg 1974; Olins and Olins 1974; Woodcock et al. 1976). The nucleosome structure has been resolved to $1.9 \AA$ (Fig. 2B; Davey et al. 2002), in which 147 base pairs of DNA are wrapped in 1.7 left-handed superhelical turns around the histone octamer to generate a $225 \mathrm{kDa}$ nucleosome core structure. The core histone octamer contains two copies of each of the four core histones, which are highly conserved in both length and amino acid sequences among eukaryotic species (Fig. 2A; Luger et al. 1997). H2A/H2B and $\mathrm{H} 3 / \mathrm{H} 4$ form stable dimers at physiological conditions. Two $\mathrm{H} 3 / \mathrm{H} 4$ dimers also form a stable tetramer under such conditions. Each core histone contains an $\sim 60$ amino acid residue histonefold domain, which accounts for $\sim 70 \%-75 \%$ of the mass of each protein (Fig. 2A) and provides a highly structured and extensive dimerization interface between the $\mathrm{H} 3 / \mathrm{H} 4$ and $\mathrm{H} 2 \mathrm{~A} / \mathrm{H} 2 \mathrm{~B}$ pairs (Fig. 2B). Each histone also has an amino-terminal tail domain, which is an intrinsically disordered region (IDR) and extends to the exterior of the nucleosome, while $\mathrm{H} 2 \mathrm{~A}$ contains an additional carboxy-terminal tail domain. Thus, a single nucleosome has 10 tails (Fig. 2C; Luger et al. 1997; Davey et al. 2002), which are highly positively charged due to a preponderance of lysines and arginines. For example, the $\sim 35$-residue $\mathrm{H} 3$ tail and the $\sim 20$-residue $\mathrm{H} 4$ tail contain 13 and 9 positively charged residues, respectively. Because of this positive charge abundance, the long, disordered tail domains contribute to the thermal stability of the nucleosome core (Ausio et al. 1989), and play important roles in the interactions between nucleosomes to contribute higher-order organization of chromatin. Chromatin is composed of nucleosomes and associated nonhistone proteins (Figs. 1B and 3; discussed later; Olins and Olins 2003).

In most eukaryotic species, an additional family of histone proteins bind to the nucleosome. Linker histones (also referred to as H1s) are highly basic proteins but share no structural homology with the core histones (Fig. 2D; Woodcock et al. 2006; Bednar et al. 2017). Interestingly, two IDRs in the carboxy- and amino-terminal regions of $\mathrm{H} 1 \mathrm{~s}$ connected by an $\sim 80$-residue "globular" domain are important for chromatin condensation (Turner et al. 2018). Whereas it is assumed that $\mathrm{H} 1 \mathrm{~s}$ bind to the exterior of nucleosomes and stabilize the wrapping of DNA within nucleosomes (Fig. 2D), H1s seem to be highly mobile in the cell (Misteli et al. 2000).

Each nucleosome particle is connected by linker DNA segments ( 20-80 bp; $6.6-27 \mathrm{~nm}$ ) that generate repetitive motifs of $\sim 200 \mathrm{bp}$ and are described as "beads on a string" or as a "10-nm fiber" (Figs. 1B and 3A; Olins and Olins 2003). This 10 -nm fiber produces electrostatic repulsion between adjacent regions because only about half of the DNA negative charges derived from the phosphate backbone are neutralized by the basic 
K. Maeshima et al.

A

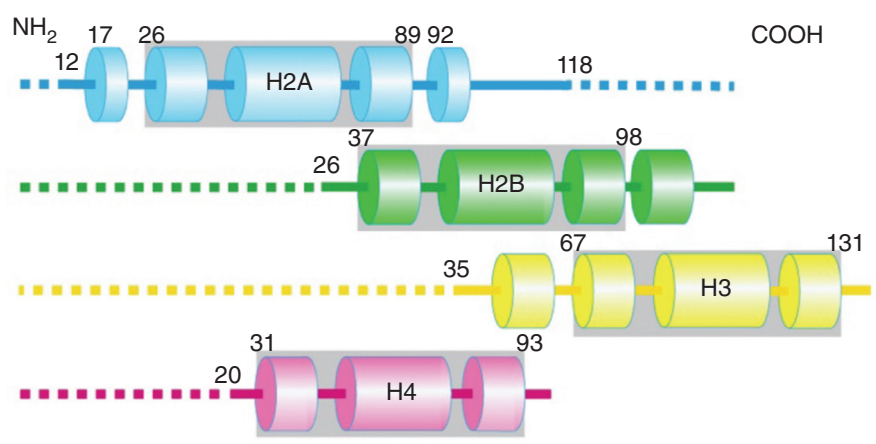

B

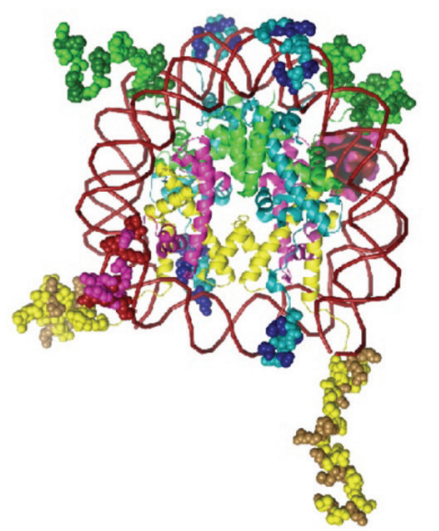

C
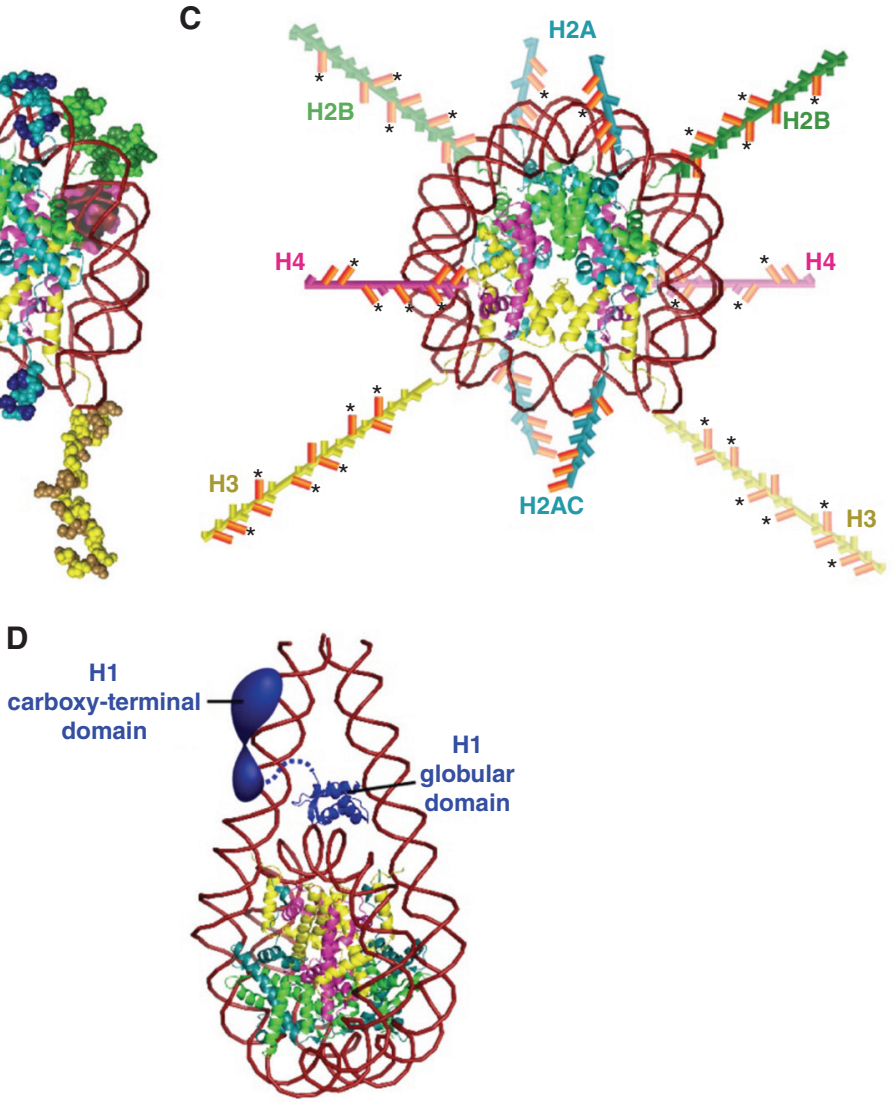

Figure 2. Structures of core histones and nucleosome. (A) Schematic of the core histone structures; histone-fold domains are enclosed by gray boxes, tail domains are denoted by dashed lines, and $\alpha$-helices are shown by columns. The positions of residues flanking the histone fold in each protein are shown. The approximate residue at the end of the tail domain nearest the histone fold is also shown. (B) The nucleosome structure at $1.9 \AA$ resolution (Davey et al. 2002). Note that histone colors correspond to A. Amino acid residues of histone tails (intrinsically disordered regions [IDRs]) are shown as ball models. Basic residues (lysines and arginines) in the tail domains are highlighted with a darker color. $(C)$ Amino-terminal tail domains in $B$ are extended away from the nucleosome core. H2A also has a carboxy-terminal tail. Basic residues (lysines and arginines) in the tail domains are colored in orange. An asterisk indicates sites of lysine acetylation. (Illustrations are based on data in Wolffe and Hayes 1999 and Pepenella et al. 2014a.) (D) Structural model of a nucleosome with a linker histone H1. (The model in $D$ was created from PDB data in Bednar et al. 2017.) 
Physical Nature of Chromatin

A

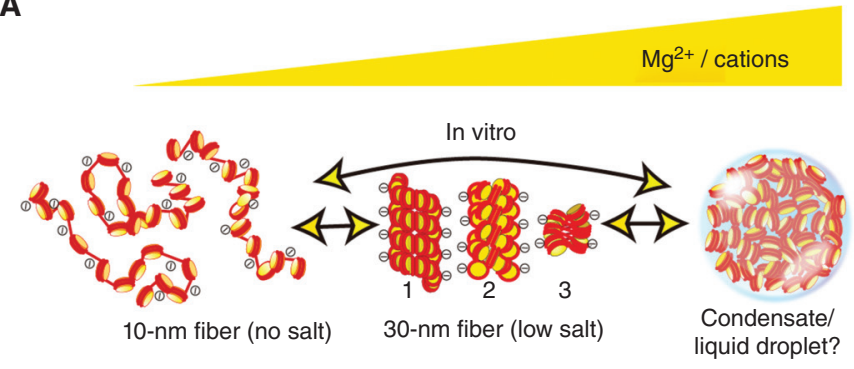

B

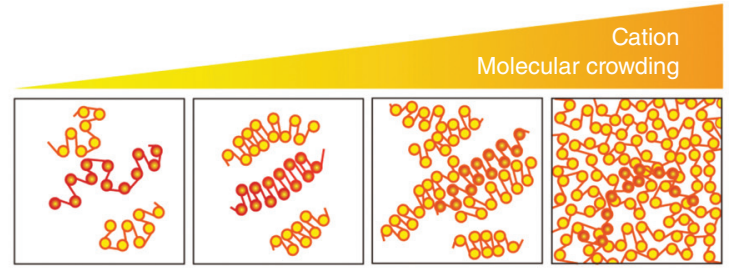

C

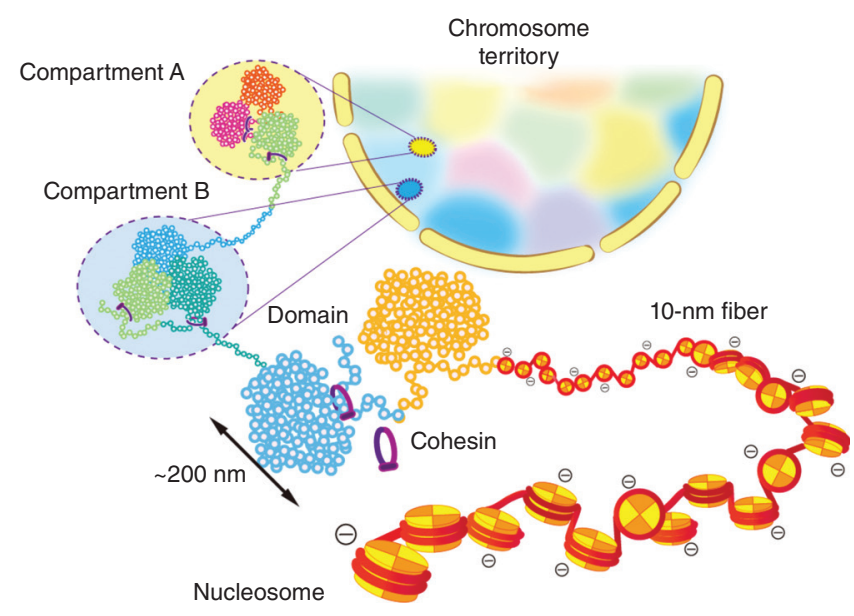

Figure 3. Chromatin structure. (A) (Left) 10-nm fibers form in no cation conditions (no salt). (Center) Three types of 30-nm fibers form with a low concentration of cations $/ \mathrm{Mg}^{2+}:(1)$ a solenoid (one-start) model, (2) a twostart zigzag, and (3) a zigzag tetranucleosomal model (Song et al. 2014). (Right) Large chromatin condensates with interdigitated $10-\mathrm{nm}$ fibers that form in more physiological cations or higher cations. Note, this condensate lacks the 30-nm structures (Maeshima et al. 2016b). Recently, under a certain specific condition, the condensates were shown to be liquid droplets formed by liquid-liquid phase separation (Gibson et al. 2019). (Panels from Maeshima et al. 2020; reproduced with modifications, with permission, from the authors.) (B) Polymer melt model. Under low cation and/or molecular crowding conditions, 10-nm fibers could form 30-nm chromatin fibers via intrafiber nucleosome associations. An increase in cation concentration and/or molecular crowding results in interfiber nucleosomal contacts that interfere with intrafiber nucleosomal associations, leading to a melted polymer-like or "sea of nucleosomes" state (Dubochet et al. 1986; Eltsov et al. 2008; Maeshima et al. 2010). In this state, tetranucleosome zigzag motifs are occasionally seen (highlighted in red). Note that we show a highly simplified two-dimensional nucleosome model in these illustrations. $(C)$ A simplified scheme for hierarchical chromatin organization in the nucleus. The 10-nm fiber is compacted into chromatin domains (e.g., topologically associating domain [TAD]/contact domain/loop domain) (Dixon et al. 2012; Nora et al. 2012; Sexton et al. 2012; Dekker and Heard 2015), which interact over long distances to form chromatin compartments (LiebermanAiden et al. 2009). Compartments generally represent a transcriptionally active or open chromatin state (compartment A) and an inactive or closed chromatin state (compartment B). A single interphase chromosome is occupied in a chromosome territory (highlighted as different colors) (Cremer and Cremer 2001). 
K. Maeshima et al.

core histones (Fig. 3A; Maeshima et al. 2014). For further folding of the 10-nm fiber, the remaining negative charges have to be screened by other factors, such as linker histones, nonhistone proteins, cations, and other positively charged molecules. Chromatin, which consists of 10-nm fibers and various nonhistone proteins, is overall still a negatively charged polymer because the negative charge of DNA is not completely neutralized by these positively charged molecules. Therefore, chromatin can dynamically change its local structure depending on the electrostatic state of its environment (Fig. 3A; Cole 1967; Earnshaw and Laemmli 1983; Hansen 2002; Hudson et al. 2003; Takata et al. 2013). Such changes in local chromatin structure are critical for gene expression because they directly govern access to the DNA and therefore impact how the genome is scanned and read in the nucleus.

\section{STRUCTURAL VARIATIONS OF CHROMATIN IN VITRO: 10-NM FIBERS, 30-NM FIBERS, AND CHROMATIN CONDENSATES}

A crucial factor that influences local chromatin structure is the ionic condition of the surrounding environment. For instance, in the presence of linker histones and a low concentration of

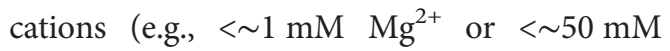
$\mathrm{Na}^{+}$), the purified 10-nm fiber (Fig. 3A, left) is folded into a zigzag or solenoidal fiber structure with a diameter of $30 \mathrm{~nm}$, which is called the 30 $\mathrm{nm}$ chromatin fiber (30-nm fiber) (Fig. 3A, center; Finch and Klug 1976; Woodcock et al. 1984; Schalch et al. 2005; Robinson et al. 2006; Song et al. 2014). Such low ionic conditions partially screen the fiber's electrostatic charge, leading to local contacts between nucleosomes in the fiber and the formation of the folded $30-\mathrm{nm}$ structure (Fig. 3A, center). Note, the concentration of cations required for this folding depends on the size and concentration of the fiber.

More cations are present at physiological concentrations that result in further charge screening. At these levels, electrostatic repulsion between neighboring nucleosomes almost disappears and large chromatin condensates form (Hansen 2002; Maeshima et al. 2016b; Gibson et al. 2019; Strickfaden et al. 2020). Such conden- sates are organized like a melted polymer or "sea of nucleosomes" and do not contain the 30-nm structure (Fig. 3A,B, right; McDowall et al. 1986; Eltsov et al. 2008; Maeshima et al. 2016a). Nucleosomes are free to contact long distal nucleosome partners, leading to interdigitation of their fibers (Fig. 3A,B, right; Zheng et al. 2005; Kan et al. 2009; Maeshima et al. 2010).

This structural variation scheme of chromatin (Fig. 3A,B) was demonstrated in vitro (Maeshima et al. 2016b) using a well-defined chromatin model, the 12-mer nucleosome array (Hansen 2002). Previous biochemical studies using the nucleosome arrays can explain why such large condensates lack the 30-nm fiber (Dorigo et al. 2003; Kan et al. 2009; Sinha and Shogren-Knaak 2010). The long tail domain of histone H4 (Fig. $2 \mathrm{~B}, \mathrm{C}$ ) mediates the formation of both the 30-nm fiber and large condensates. Consequently, organization into chromatin condensates can prevent the formation of 30-nm fibers by sequestering the H4 tail. It is also important to note that this interdigitated chromatin folding might contribute to forming large chromatin structures such as mitotic chromosomes (Hansen et al. 2018).

The physical state of chromatin condensates is intriguing and a subject of ongoing research. Gibson et al. showed that nucleosome arrays with cations developed into large chromatin condensates $\sim 10 \mu \mathrm{m}$ in size. The resultant large condensates behaved like liquid droplets (Fig. 3A, right; Gibson et al. 2019), in which the nucleosomes self-organized through a process termed liquidliquid phase separation (LLPS) (Hyman et al. 2014; Mitrea and Kriwacki 2016; Rippe 2021). The droplets rapidly fused to each other and the fluorescence recovery after photobleaching (FRAP) showed that fluorescently labeled nucleosome arrays freely diffused in the droplets (Gibson et al. 2019). However, Strickfaden et al. (2020) revealed that the condensates formed from similar nucleosome arrays show a rather solid-like property and that the liquid chromatin condensates, as shown by Gibson et al. (2019), were only observed under a highly specific set of conditions (Strickfaden et al. 2020). The condensates thus seem to have solid-like features at a micron scale. Nonetheless, we infer that the condensates might have weak intrinsic droplet prop- 
erties at a nanoscale (100-200 $\mathrm{nm})$ range, given that each nucleosome possesses 10 IDRs (Fig. 2B, C; Luger et al. 1997; Pepenella et al. 2014b). IDRs often mediate multivalent contacts for droplet formation (Lin et al. 2015). Emerging evidence suggests that functional compartmental droplets are formed by LLPS in the cell (Hyman et al. 2014; Mitrea and Kriwacki 2016). Further investigation will be required to examine the intrinsic droplet property in the condensates.

\section{CHROMATIN ORGANIZATION IN THE NUCLEUS}

In 1976 , the 30 -nm fiber was discovered in vitro and has since been believed to be the basic chromatin structure in eukaryotic cells (Fig. 3A, center; Finch and Klug 1976; Woodcock et al. 1984; Schalch et al. 2005; Robinson et al. 2006; Song et al. 2014). However, during the past 10 years, extensive data from various techniques, including cryo-electron microscopy (EM) (McDowall et al. 1986; Eltsov et al. 2008; Chen et al. 2016; Cai et al. 2018), X-ray scattering (Joti et al. 2012; Nishino et al. 2012), electron spectroscopic imaging (ESI) (Fussner et al. 2012; Visvanathan et al. 2013), EM tomography (Ou et al. 2017), stochastic optical reconstruction microscopy (STORM) (Ricci et al. 2015), chromosome conformation capture (3C)/ Hi-C (Dekker 2008; Hsieh et al. 2015; Sanborn et al. 2015; Ohno et al. 2019), and computational modeling (Collepardo-Guevara and Schlick 2014; Bajpai et al. 2017), demonstrated that chromatin consists of rather irregular and variable nucleosome arrangements like "sea of nucleosomes" (Fig. 3A,B, right). In addition to the cation issue discussed above, many factors in native chromatin, including irregular nucleosome spacing, histone modifications and variants, and nonhistone protein binding, would preclude the formation of regular 30-nm fibers, especially in actively transcribing cells. Thus, the $30-\mathrm{nm}$ fiber is unlikely to be the basic structure or unit of chromatin in vivo. Nonetheless, the formation of tetranucleosome motifs is highly possible (Baldi et al. 2020; Krietenstein and Rando 2020), as reported by new genomics studies that found occasional zigzag nucleosome configurations in budding yeast cells (Hsieh et al. 2015;
Ohno et al. 2019) and in heterochromatin regions of human cells (Risca et al. 2017).

At a higher level of organization, a large-scale chromatin structure with a diameter $\sim 200 \mathrm{~nm}$ has long been observed by light and electron microscopic imaging in more complex eukaryotes (Fig. 3C; Hu et al. 2009; Nozaki et al. 2017; Olins and Olins 2018; Xu et al. 2018), while yeast cells seem to have predominately open chromatin arrangements with clusters of only a few nucleosomes (Hsieh et al. 2015; Chen et al. 2016; Ohno et al. 2019). Recently, a combination of 3D superresolution and scanning EM revealed "chromatin domains," which were observed as irregularly sized clusters of nucleosomes ( $200 \mathrm{~nm})$ (Hoffman et al. 2020; Miron et al. 2020). Interestingly, the chromatin domains in euchromatic regions maintained compact chromatin organizations with active epigenetic marks, but their sizes were smaller than those of heterochromatin, which is consistent with the previous reports (Maeshima et al. 2015; Nozaki et al. 2017). ESI, which maps phosphorus and nitrogen atoms with contrast and resolution sufficient to visualize 10-nm fibers (Hendzel et al. 1999), also exhibited such chromatin domain structures (Strickfaden et al. 2020).

$3 \mathrm{C} / \mathrm{Hi}-\mathrm{C}$ methods can be used to generate a fine contact probability map of genome DNA (Dekker and Heard 2015; Dekker 2021), and this technology has revealed that the higher eukaryotic genome is partitioned into chromatin domains (Fig. 3C): topologically associating domains (TADs) at the scale of several hundreds of kilobytes (Dixon et al. 2012; Nora et al. 2012; Sexton et al. 2012) and smaller contact/loop domains (mean size of $\sim 185 \mathrm{~kb}$ ) (Rao et al. 2014). These structures were confirmed visually by superresolution imaging (Bintu et al. 2018). The loop domains seemed to be held together by cohesin (Figs. 3C and 5C,E), in cooperation with CCCTC-binding factor (CTCF) (Zuin et al. 2014; Rao et al. 2017; Wutz et al. 2017; Bintu et al. 2018; for more details, see Dekker 2021). These domains are often clustered as two distinct, megabase scale compartments A and B (Lieberman-Aiden et al. 2009), which likely represent transcriptionally active chromatin and inactive chromatin, respectively (Fig. 3C). Collectively, 
K. Maeshima et al.

chromatin organization in the nucleus appears to have a hierarchy (Fig. 3C): from 10-nm fibers to domains, domains to compartments $\mathrm{A}$ and $\mathrm{B}$, and from these compartments to chromosomes to form the "chromosome territory" of the nucleus (Cremer and Cremer 2001).

The large-scale arrangements/domains described above seem to be fundamental chromatin features in the nucleus (Misteli 2020). Notably, the domains have a compact organization (Fig. 3C), irrespective of euchromatin or heterochromatin (Nozaki et al. 2017; Miron et al. 2020; Strickfaden et al. 2020). To form these compact domains, local nucleosomenucleosome interactions seem to be critical (Nozaki et al. 2017; Strickfaden et al. 2020). Cations like magnesium ion $\left(\mathrm{Mg}^{2+}\right)$ can facilitate these interactions, as shown in the formation of cation $\left(\mathrm{Mg}^{2+}\right)$-dependent chromatin condensates in vitro, which requires nucleosome-nucleosome interactions by histone tails (Fig. 2C; Maeshima et al. 2016b; Gibson et al. 2019; Sanulli et al. 2019; Strickfaden et al. 2020).

Furthermore, it is very likely that non-nucleosomal proteins and RNAs, as well as cations, contribute to the formation of compact chromatin domains through macromolecular crowding effects (Figs. 3B and 5E; Asakura and Oosawa 1954; Marenduzzo et al. 2006; Hancock 2007). Imai et al. (2017) found that the total density of heterochromatin $(208 \mathrm{mg} / \mathrm{mL})$ was only 1.53 fold higher than that of the euchromatic regions $(136 \mathrm{mg} / \mathrm{mL})$, while the DNA density of heterochromatin was 5.5-7.5-fold higher (Imai et al. 2017). This finding suggests that non-nucleosomal materials (proteins, RNAs, etc.), which are dominant in both heterochromatin and euchromatin $(\sim 120 \mathrm{mg} / \mathrm{mL})$, play an important role in compact organization of the domains in the nuclear crowded environments.

The organization of chromatin may serve to modulate the accessibility of larger protein complexes to target sites (Maeshima et al. 2015; Miron et al. 2020). The compact domains might hinder the access of large protein complexes such as transcription factors and replication initiation complexes to the inner core of chromatin domains (Maeshima et al. 2015; Miron et al. 2020). Decompaction of such domains with his- tone modifications or the action of other proteins can increase accessibility to the complexes to turn on gene transcription (Toth et al. 2004; Bian and Belmont 2012; Kieffer-Kwon et al. 2017; Nozaki et al. 2017; Miron et al. 2020; Strickfaden et al. 2020). Interestingly, it has been suggested that various RNAs may be involved in the regulation of these compact chromatin domains (Nozawa and Gilbert 2019). Nozawa et al. (2017) showed that scaffold attachment factor A (SAFA)/heterogeneous nuclear ribonucleoprotein $U$ (hnRNP U) decompacts transcriptionally active chromatin domains by forming a filamentshaped oligomer with nuclear RNA (Nozawa et al. 2017). How RNAs act on the domain formation remains unclear and is an area to be investigated further.

Whereas the compact organization of the genome appears to be primarily designed for storage efficiency, it seems to have additional functional roles to protect genomic information. The compact organization can generate a springlike restoring force that resists nuclear deformation by mechanical stress and plays an important role in maintaining genomic integrity. Nuclei with condensed chromatin possess significant elastic rigidity, while those with decondensed chromatin are considerably softer (Shimamoto et al. 2017; Stephens et al. 2017; Maeshima et al. 2018b; Agbleke et al. 2020; also see Miroshnikova and Wickström 2021). Interestingly, compact chromatin seems more resistant to radiation and chemical damage than the decondensed form, probably because condensed chromatin has lower reactive radical generation and is less prone to chemical attack (Takata et al. 2013). The maintenance of genomic DNA integrity by greater compaction may have contributed to the evolution of eukaryotic organisms.

\section{LOCAL MOTION OF CHROMATIN IN THE NUCLEUS}

The view of chromatin organization discussed so far suggests that chromatin is less physically constrained and more dynamic than expected in the regular static structure model with helical coiling (Maeshima et al. 2010). In addition, given that each nucleosome possesses 10 IDRs (Fig. 
2C; Luger et al. 1997; Pepenella et al. 2014b), it is tempting to consider that chromatin locally behaves like a liquid (Fig. 3A,B, right).

Live-cell imaging studies using a LacO/LacIGFP system (Fig. 4A; Robinett et al. 1996) or related systems (Germier et al. 2017; Tasan et al. 2018; Eykelenboom et al. 2019) have long revealed dynamic movements of chromatin in numerous cells such as yeast, nematodes, flies, and mammals (Marshall et al. 1997; Heun et al. 2001; Chubb et al. 2002; Levi et al. 2005; Meister et al. 2010; Hajjoul et al. 2013; Arai et al. 2017). This system can track the motion of bacterial operator ( $\mathrm{LacO})$ repeats ( $<256$ repeats) inserted into the genome of living cells to which fluorescent LacI proteins bind (Fig. 4A; Robinett et al. 1996). Analyses of FRAP have also demonstrated turnover rates of histones or chromatin-associated proteins at bleaching sites in living cells and provided indirect information on chromatin motion (Misteli et al. 2000; Kimura and Cook 2001; Meshorer et al. 2006). Furthermore, CRISPR-based genome editing technology has allowed a targeted region of interest in genome chromatin to be specifically labeled (e.g., Tasan et al. 2018) to visualize motion of that region (Fig. 4B; Chen et al. 2013; Gu et al. 2018; Guo et al. 2019; Ma et al. 2019).

Moreover, genome-wide local chromatin motion has been investigated using single-nucleosome imaging and tracking in living cells through fluorescently tagged histone proteins (Fig. 4C; Hihara et al. 2012; Nozaki et al. 2017; Nagashima et al. 2019; Lerner et al. 2020; GómezGarcía et al. 2021). This powerful imaging modality can trace the movement of nucleosomes throughout the nucleus at the single-molecule level with high resolution. Similar global chromatin movements have been described using fluorescently labeled bulk histones, or DNA-binding dye, to analyze their displacement correlation (Fig. 4D; Zidovska et al. 2013; Shaban et al. 2020). Development of imaging techniques that record local chromatin motion at a genome-wide scale enabled visualization of heterogeneity of local chromatin motion in a whole nucleus as a chromatin heat map (Fig. 4E,F; Nozaki et al. 2017; Nagashima et al. 2019) or chromatin dynamics maps (Zidovska et al. 2013; Lerner et al. 2020; Shaban et al. 2020). These maps show over- all distributions of heterochromatin and euchromatin. As expected, the local chromatin motion at the nuclear periphery (heterochromatin) is less mobile (Fig. 4F). Consistently, statistical analysis of genome-wide single-nucleosome tracking data revealed heterogeneity of movements, which roughly categorized chromatin into two types: slow chromatin that moves under structurally constrained environments and fast chromatin that moves with fewer constraints (Fig. 4G; Ashwin et al. 2019, 2020). Lerner et al. (2020) suggested a correlation between chromatin mobility and transcription factor binding. Furthermore, statistical analysis of single-nucleosome tracking data has unveiled that the organized nucleosomes within chromatin are locally mobile and behave like a liquid at the scale of less than hundreds of nanometers (Ashwin et al. 2019, 2020). In other words, when considered at the scale of the chromatin domain, chromatin is very dynamic and exhibits a liquid-like diffusion rather than a crystal-like structure, which has a long-range order. A physical basis of the liquid-like behavior of chromatin is provided by polymorphism of the $10-\mathrm{nm}$ fiber with the long histone tails (Fig. 2C), which can turn into various structures, including extended, folded, interdigitated, bent, and looped structures (Collepardo-Guevara and Schlick 2014).

\section{FACTORS THAT CONSTRAIN CHROMATIN MOTION IN THE NUCLEUS}

Whereas local chromatin behaves like a liquid (Ashwin et al. 2019, 2020), each chromosome occupied in the territory appears to be relatively stable, without mixing of chromosomes (Fig. 3C; Strickfaden et al. 2020). Certainly, the mean square displacement (MSD) analysis of local nucleosome motion in living human cells revealed that the plots almost reached a plateau value after $3 \mathrm{sec}$ (Fig. 5A,B), which is proportional to the square of the radius of constraint (Rc; $P=6 / 5 \times$ $\mathrm{Rc}^{2}$ ) (Dion and Gasser 2013). In addition, the estimated radius of the nucleosome motion constraint in living human RPE-1 cells is $141 \pm$ $19.2 \mathrm{~nm}$ (mean $\pm \mathrm{SD}$ ), which roughly corresponds to the size of the chromatin domain mentioned above (i.e., local chromatin is constrained 
K. Maeshima et al.
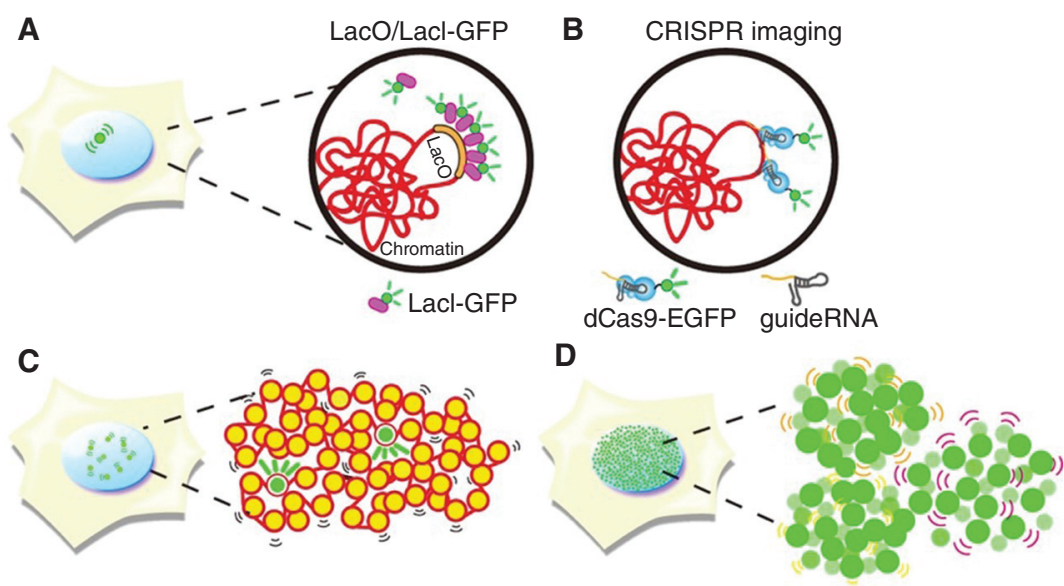

E

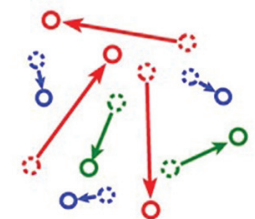

Chromatin dynamics

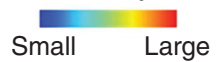

$\mathbf{F}$

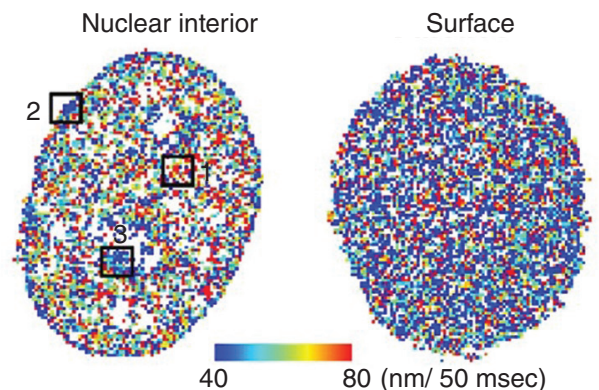

G

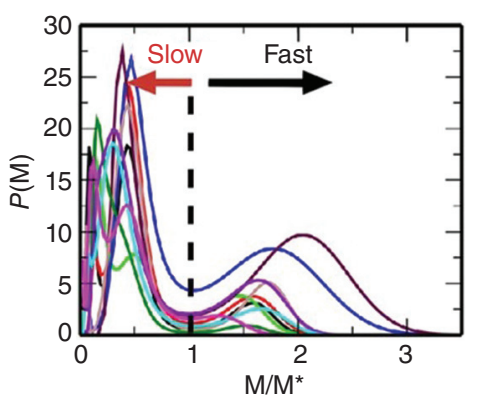

Figure 4. Visualization of local chromatin motion. Schematics for $(A)$ LacO/LacI-GFP, $(B)$ CRISPR-based chromatin labeling, $(C)$ single nucleosome imaging and tracking, and $(D)$ bulk chromatin labeling for displacement correlation analyses. A small number of nucleosomes are labeled with photoactivatable GFP or other fluorescent tags for single nucleosome imaging in $C$ while much more are labeled in $D$. (E) Example of chromatin dynamics used to generate a heat map. Movements are measured over $50 \mathrm{msec}$. Small movements are shown in blue and large movements are shown in red. Heat maps allow the visualization of the heterogeneity of local chromatin motion in the nucleus. $(F)$ Diagrams of a chromatin heat map where the nuclear interior (left) and nuclear periphery (right) of a living HeLa cell are shown. The boxed regions 1-3 show nucleoplasm, nuclear periphery, and around nucleolus periphery, respectively. Note that regions 2 and 3 are presumably heterochromatin regions shown in dark blue. The map of the nuclear periphery (surface) appears more bluish, showing less mobile chromatin in the heterochromatin-rich regions. $(G)$ Mean square displacement (MSD) distribution of local chromatin motion. The MSD at the first minimum between the peaks is denoted by $\mathrm{M}^{*} . P(\mathrm{M}, 0.5 \mathrm{sec})$ from 10 cell samples were scaled by $\mathrm{M}^{*}$ and shown, indicating fast and slow peaks. For details, see Ashwin et al. (2019). (Illustrations and legend from Maeshima et al. 2020; reproduced with modifications, with permission, from the authors.) 
A

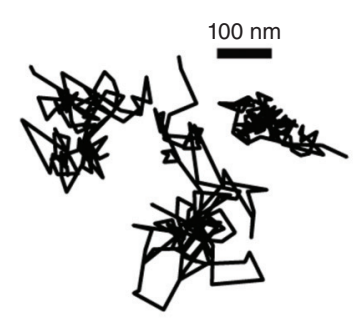

C

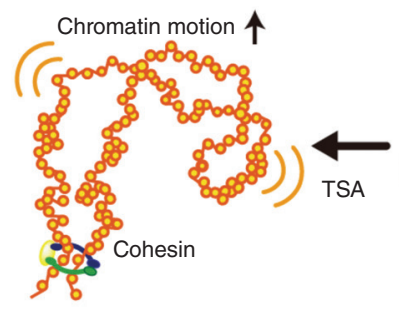

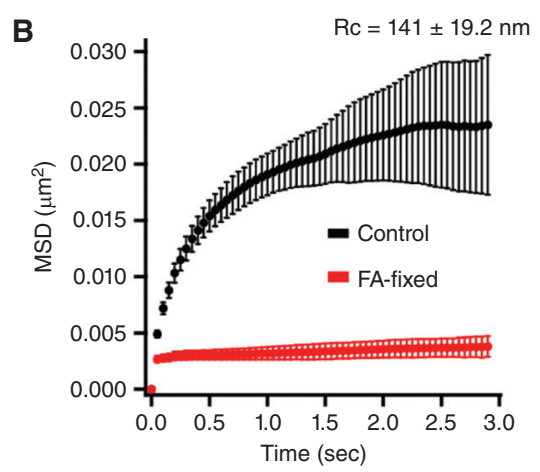

B
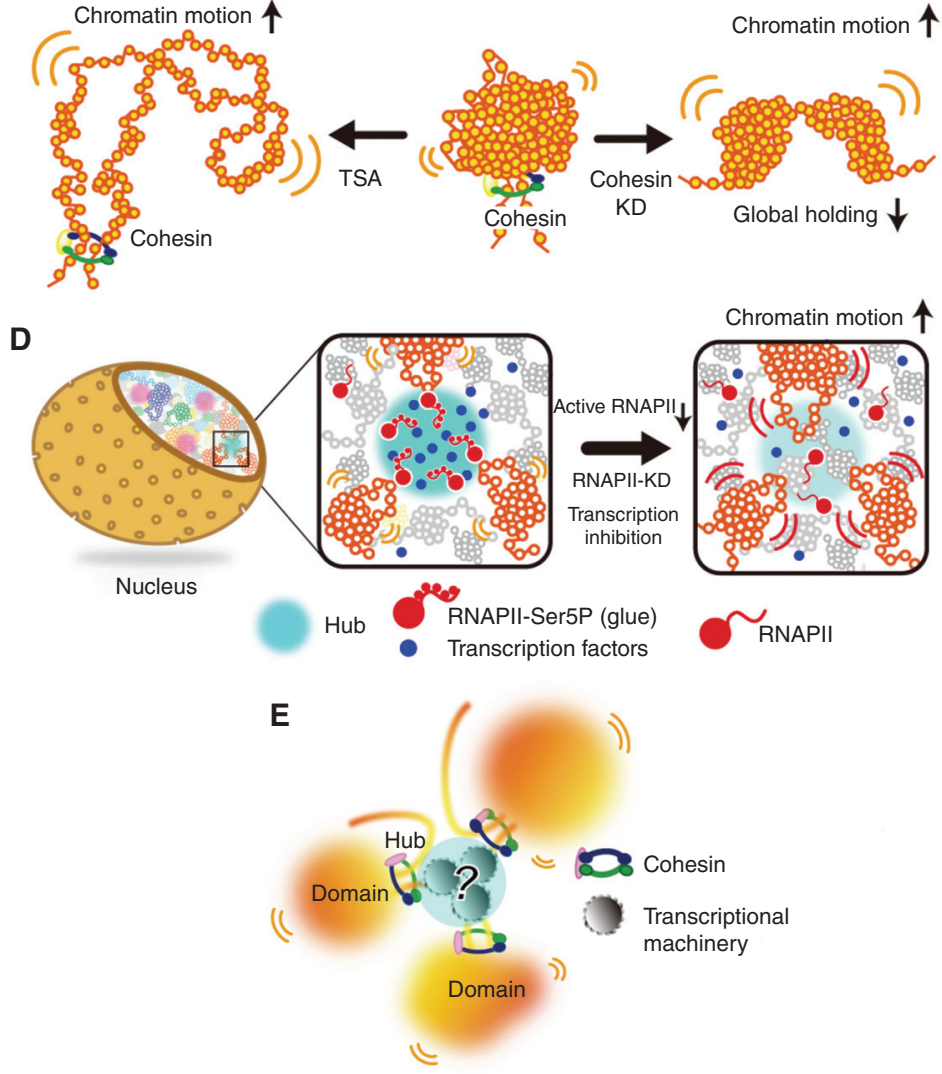

Figure 5. Local chromatin motion and chromatin domains in the nucleus. (A) Three representative trajectories of single nucleosomes (Nagashima et al. 2019). (B) Mean square displacement (MSD) plots ( \pm SD among cells) of single nucleosomes in living (black) and formaldehyde-fixed (red) RPE-1 cells over time ( 0.05 to $3 \mathrm{sec}$ ). For each sample, $n=20$ cells. (Data from Nagashima et al. 2019.) (C) (Left) Decondensed chromatin in cells treated with histone deacetylase (HDAC) inhibitor trichostatin A (TSA) shows increased chromatin movements resulting from weakened nucleosome-nucleosome interactions and subsequently less local chromatin constraining. (Center) Usual state of chromatin with reduced movements. The chromatin domain is organized by local nucleosome-nucleosome interactions and global holding by cohesin. (Right) Loss of cohesin leads to less constraining and a resultant increase in chromatin motion. (D) (Left and center), Cluster/condensate of active RNA polymerase II (RNAPII) and transcription factors (blue spheres) can work as a transient hub (cyan sphere) to weakly connect multiple chromatin domains and to globally constrain chromatin motion. (Right) RNAPII inhibition, or its rapid depletion, releases chromatin constraints and increases chromatin motion. (E) A current model of chromatin domains. Chromatin is locally very dynamic, but the local chromatin motion is constrained by various physical or geometrical factors to keep each chromosome in the chromosome territories. (Diagrams in panels $C$ and $D$ from Babokhov et al. 2020; reproduced with modifications, with permission, from the authors.) 
K. Maeshima et al.

to a range of the chromatin domain size and does not appear to travel long distances) (Fig. 3C; Nagashima et al. 2019). Furthermore, the DNA replication foci observed via pulse fluorescent labeling revealed constrained euchromatin and heterochromatin behavior in living mouse cells (Strickfaden et al. 2020). These properties are not consistent with liquid behavior and suggest highly constrained motion. If chromatin behaves like a liquid locally but does not move over long distances, what constrains the chromatin in a nuclear aqueous environment? How are chromosome territories maintained? How can chromatin motion be adjusted depending on the physiological state(s) of the cell?

In contrast to ATP-dependent long-range movements of chromatin (see reviews by Soutoglou and Misteli 2007; Seeber et al. 2018), local chromatin motion is likely to be isotropic and primarily driven by thermal fluctuation (Fig. 5A; Marshall et al. 1997; Chubb et al. 2002; Levi et al. 2005; Nozaki et al. 2017; Ashwin et al. 2019). Variability in this motion can be created by constraints from several physical or geometrical factors (Fig. 4G; Ashwin et al. 2019).

\section{Nucleosome Interactions}

Nucleosome-nucleosome interactions are one of the factors to constrain chromatin motion. Chromatin becomes more mobile when treated with the histone deacetylase (HDAC) inhibitor trichostatin A (TSA) (Fig. 5C, left). This drug increases histone $\mathrm{H} 3$ and $\mathrm{H} 4$ tail acetylation (Fig. 2C) and decondenses chromatin (Fig. 5C, left), presumably by decreasing the number of nucleosome-nucleosome interactions (Gorisch et al. 2005; Ricci et al. 2015; Nozaki et al. 2017; Strickfaden et al. 2020). Such artificial decondensation of chromatin (i.e., extended fibers or fibers with nucleosome-free regions) reduces constraints that restrict thermal-fluctuating motion and results in elevated local chromatin movement (Fig. 5C, left; Amitai et al. 2017; Nozaki et al. 2017; Ashwin et al. 2019).

\section{Nucleoplasmic Milieu}

Another factor is the quantity of free cations in the nucleus. An increase in cations, such as
$\mathrm{Mg}^{2+}$, can condense chromatin and lower its local motion, since nucleosomes have residual negative charges and tend to repulse one another as discussed above (Fig. 3A,B). Consistently, intracellular ATP reduction, which releases $\mathrm{Mg}^{2+}$ from ATP-Mg (Maeshima et al. 2018a), hypercondenses chromatin and decreases its motion (Visvanathan et al. 2013; Nozaki et al. 2017; Maeshima et al. 2018a). These findings offer a regulatory mechanism for the higher-order chromatin organization by the intracellular $\mathrm{Mg}^{2+}$-ATP balance. Since intracellular ATP levels vary depending on cell types (Pecqueur et al. 2013; Qian et al. 2014; Kieffer-Kwon et al. 2017), they may regulate cellular functions such as differentiation via changing higher-order chromatin organization. Moreover, hypertonic treatment ( $\sim 570 \mathrm{mOsm}$ ) had similar effects (Albiez et al. 2006; Nozaki et al. 2017; Strickfaden et al. 2020). This may be due to an increase in intracellular cations and molecular crowding following hypertonic treatment (Albiez et al. 2006).

\section{Chromatin Proteins}

Various chromatin proteins constrain the local chromatin motion driven by thermal fluctuation, contributing to the retention of each chromosome in its "chromosome territory" (Fig. 3C; Cremer and Cremer 2001) as well as genome functions. The cohesin complex is an important protein complex that can capture chromatin fibers with its ring structure to form loops and for sister chromatid cohesion (Nasmyth and Haering 2005; Morales and Losada 2018; Nishiyama 2019). Loss of cohesin leads to fewer chromatin constraints and thereby a drastic increase in local chromatin motion (Fig. 5C, right; Dion et al. 2013; Nozaki et al. 2017; Ashwin et al. 2019; Itoh et al. 2021).

\section{Transcription}

Interestingly, the RNA transcriptional machinery has a constraining role for local chromatin motion in the nucleus (Fig. 5D,E; Nagashima et al. 2019; Babokhov et al. 2020; Itoh et al. 2021). Knockdown of active RNA polymerase II (RNAPII) or other transcription regulatory 
factors, as well as RNAPII inhibitor treatments, releases RNAPII from chromatin and raises local chromatin movements (Nagashima et al. 2019). Consistent with this finding, some specific genomic loci in human breast cancer and fly embryos became less dynamic when actively transcribed (Germier et al. 2017; Chen et al. 2018). Furthermore, it was recently shown that active RNA polymerase I (RNAPI) also forms clusters (Andrews et al. 2018) and constrains ribosomal DNA chromatin in the nucleoli (Ide et al. 2020). In this case, transcription inhibition dissociated RNAPI from rDNA chromatin and moved like a liquid within the newly formed droplet in the nucleolus (Ide et al. 2020). The concept that the transcriptional machinery constrains chromatin (Fig. 5D,E) is consistent with the classic transcription factory hypothesis (Cook 1999; Edelman and Fraser 2012; Feuerborn and Cook 2015), where clusters of RNAPII and other transcription factors immobilize genome chromatin to facilitate transcription. Recent studies also suggest that RNAPII, Mediator, and other factors form condensate/clusters upon transcription (Cho et al. 2018; Chong et al. 2018; Lu et al. 2018; Sabari et al. 2018).

\section{Association with Chromatin Domains}

Other prominent chromatin constraining factors are the proteins associated with heterochromatin, where the chromatin is less mobile (Fig. 4F; Chubb et al. 2002; Shinkai et al. 2016; Nozaki et al. 2017; Nagashima et al. 2019; Lerner et al. 2020). The nuclear periphery lamina-associated chromatin domains (LADs) enriched regions (van Steensel and Belmont 2017) have more heterochromatin marker di- and trimethylation of histone $\mathrm{H} 3$ lysine 9 (H3K9me2/3) and HP1 protein (Machida et al. 2018). Inner nuclear membrane proteins (Pawar and Kutay 2021) such as lamins (Reddy 2021), together with HP1, may constrain chromatin movement (Fig. 4F; Chubb et al. 2002; Shinkai et al. 2016; Nozaki et al. 2017; Nagashima et al. 2019; Lerner et al. 2020). The pericentric heterochromatin regions in mouse cells (Maison et al. 2010) are also enriched with the H3K9me2/3 and HP1 protein, which can cross-link nucleosomes (Machida et al.
2018) and restrict chromatin motion (Fig. 4F; Nozaki et al. 2017; Lerner et al. 2020). Whereas HP1 was suggested to form liquid droplets by LLPS (Larson et al. 2017; Strom et al. 2017), Erdel et al. (2020) recently reported that LLPS may not be a prerequisite for the chromatin cross-link function of HP1 (for details, see Rippe 2021). Whether condensates/clusters/liquid droplets of other nuclear bodies can stabilize the genome chromatin for their functions remains unclear and an area to be investigated.

\section{PERSPECTIVES}

The physical nature of chromatin in the nucleus, discussed in this review, is functionally important for gene regulation and control of gene expression. Therefore, defects in the physical nature may be relevant for physiological and pathological processes (Misteli 2010; see Khan 2021). It is known that mutations and transcriptional misregulation of several "global genome organizers," such as the cohesin complex (Misteli 2010; Kline et al. 2018), are linked to human diseases. Interestingly, some mutations in core histones act as oncogenic drivers, creating the term "oncohistones" (Bennett et al. 2019; Nacev et al. 2019). For example, several mutations in the histone variant $\mathrm{H} 3.3$ have been reported in pediatric gliomas (Schwartzentruber et al. 2012; $\mathrm{Wu}$ et al. 2012). Among these, the dominantnegative H3.3 K27M mutant, where the 27th Lys is replaced by Met, inhibits the activity of the Polycomb repressor complex 2 (PRC2) to methylate $\mathrm{H} 3 \mathrm{~K} 27$, resulting in impaired transcriptional silencing (Chan et al. 2013; Lewis et al. 2013). H2B Glu76 and H3.1 Glu97 mutations are also frequently found in cancer cells, and replacement of these residues with Lys leads to nucleosome instability (Arimura et al. 2018). Furthermore, mutations in the genes that encode several linker histone $\mathrm{H} 1$ isoforms are highly recurrent in B-cell lymphomas (Yusufova et al. 2021). Whereas how these mutations enhance tumorigenesis remains unclear, their resultant altered behaviors may be involved in the process. Such alterations might affect transcription, DNA repair efficiency, or plasticity of chromatin in the nucleus (Shimamoto et al. 
K. Maeshima et al.

2017; Stephens et al. 2017; Nagashima et al. 2019; also see Miroshnikova and Wickström 2021). Discovering how altering the physical properties of chromatin contributes to creating cell abnormalities and subsequent human disorders, including tumorigenesis, is an exciting area for future research.

\section{ACKNOWLEDGMENTS}

We are grateful to Dr. Y. Hiromi, Dr. Y. Itoh, and Dr. K.M. Marshall for critical reading and editing of this manuscript. We thank Dr. M. Sasai, Dr. Belmont, Dr. Rando, and Maeshima laboratory members for helpful discussions and support. We apologize that space limitations rendered us unable to mention many important works and papers on chromatin structure and dynamics. This work was supported by the Japan Society for the Promotion of Science (JSPS) and MEXT KAKENHI Grants (19H05273 and 20H05936), a Japan Science and Technology Agency CREST Grant (JPMJCR15G2), the Takeda Science Foundation, and the Uehara Memorial Foundation.

\section{REFERENCES}

${ }^{*}$ Reference is also in this collection.

Agbleke AA, Amitai A, Buenrostro JD, Chakrabarti A, Chu L, Hansen AS, Koenig KM, Labade AS, Liu S, Nozaki T, et al. 2020. Advances in chromatin and chromosome research: perspectives from multiple fields. Mol Cell 79: 881-901. doi:10.1016/j.molcel.2020.07.003

Albiez H, Cremer M, Tiberi C, Vecchio L, Schermelleh L, Dittrich S, Küpper K, Joffe B, Thormeyer T, von Hase J, et al. 2006. Chromatin domains and the interchromatin compartment form structurally defined and functionally interacting nuclear networks. Chromosome Res 14: 707733. doi:10.1007/s10577-006-1086-x

Amitai A, Seeber A, Gasser SM, Holcman D. 2017. Visualization of chromatin decompaction and break site extrusion as predicted by statistical polymer modeling of single-locus trajectories. Cell Rep 18: 1200-1214. doi:10 .1016/j.celrep.2017.01.018

Andrews JO, Conway W, Cho WK, Narayanan A, Spille JH, Jayanth N, Inoue T, Mullen S, Thaler J, Cissé II. 2018. qSR: a quantitative super-resolution analysis tool reveals the cell-cycle dependent organization of RNA polymerase I in live human cells. Sci Rep 8: 7424. doi:10.1038/s41598018-25454-0

Arai R, Sugawara T, Sato Y, Minakuchi Y, Toyoda A, Nabeshima K, Kimura H, Kimura A. 2017. Reduction in chromosome mobility accompanies nuclear organization dur- ing early embryogenesis in Caenorhabditis elegans. Sci Rep 7: 3631. doi:10.1038/s41598-017-03483-5

Arimura Y, Ikura M, Fujita R, Noda M, Kobayashi W, Horikoshi N, Sun J, Shi L, Kusakabe M, Harata M, et al. 2018. Cancer-associated mutations of histones H2B, H3.1 and H2A.Z.1 affect the structure and stability of the nucleosome. Nucleic Acids Res 46: 10007-10018.

Asakura S, Oosawa F. 1954. On interaction between two bodies immersed in a solution of macromolecules. $J$ Chem Phys 22: 1255-1256. doi:10.1063/1.1740347

Ashwin SS, Nozaki T, Maeshima K, Sasai M. 2019. Organization of fast and slow chromatin revealed by singlenucleosome dynamics. Proc Natl Acad Sci 116: 1993919944. doi:10.1073/pnas.1907342116

Ashwin SS, Maeshima K, Sasai M. 2020. Heterogeneous fluid-like movements of chromatin and their implications to transcription. Biophys Rev 12: 461-468. doi:10.1007/ s12551-020-00675-8

Ausio J, Dong F, van Holde KE. 1989. Use of selectively trypsinized nucleosome core particles to analyze the role of the histone "tails" in the stabilization of the nucleosome. J Mol Biol 206: 451-463. doi:10.1016/0022-2836 (89)90493-2

Babokhov M, Hibino K, Itoh Y, Maeshima K. 2020. Local chromatin motion and transcription. J Mol Biol 432: 694700. doi:10.1016/j.jmb.2019.10.018

Bajpai G, Jain I, Inamdar MM, Das D, Padinhateeri R. 2017. Binding of DNA-bending non-histone proteins destabilizes regular 30-nm chromatin structure. PLoS Comput Biol 13: e1005365. doi:10.1371/journal.pcbi.1005365

Baldi S, Korber P, Becker PB. 2020. Beads on a string-nucleosome array arrangements and folding of the chromatin fiber. Nat Struct Mol Biol 27: 109-118. doi:10.1038/ s41594-019-0368-x

Bednar J, Garcia-Saez I, Boopathi R, Cutter AR, Papai G, Reymer A, Syed SH, Lone IN, Tonchev O, Crucifix C, et al. 2017. Structure and dynamics of a $197 \mathrm{bp}$ nucleosome in complex with linker histone H1. Mol Cell 66: 729. doi:10.1016/j.molcel.2017.05.018

Bennett RL, Bele A, Small EC, Will CM, Nabet B, Oyer JA, Huang X, Ghosh RP, Grzybowski AT, Yu T, et al. 2019. A mutation in histone $\mathrm{H} 2 \mathrm{~B}$ represents a new class of oncogenic driver. Cancer Discov 9: 1438-1451. doi:10.1158/ 2159-8290.CD-19-0393

Bian Q, Belmont AS. 2012. Revisiting higher-order and large-scale chromatin organization. Curr Opin Cell Biol 24: 359-366. doi:10.1016/j.ceb.2012.03.003

Bianconi E, Piovesan A, Facchin F, Beraudi A, Casadei R, Frabetti F, Vitale L, Pelleri MC, Tassani S, Piva F, et al. 2013. An estimation of the number of cells in the human body. Annals Hum Biol 40: 463-471. doi:10.3109/ 03014460.2013.807878

Bintu B, Mateo LJ, Su JH, Sinnott-Armstrong NA, Parker M, Kinrot S, Yamaya K, Boettiger AN, Zhuang X. 2018. Super-resolution chromatin tracing reveals domains and cooperative interactions in single cells. Science 362: eaau1783. doi:10.1126/science.aau1783

Cai S, Chen C, Tan ZY, Huang Y, Shi J, Gan L. 2018. Cryo-ET reveals the macromolecular reorganization of $S$. pombe mitotic chromosomes in vivo. Proc Natl Acad Sci 115: 10977-10982. doi:10.1073/pnas.1720476115 
Chan KM, Fang D, Gan H, Hashizume R, Yu C, Schroeder M, Gupta N, Mueller S, James CD, Jenkins R, et al. 2013. The histone H3.3K27M mutation in pediatric glioma reprograms H3K27 methylation and gene expression. Genes Dev 27: 985-990. doi:10.1101/gad.217778.113

Chen B, Gilbert LA, Cimini BA, Schnitzbauer J, Zhang W, Li GW, Park J, Blackburn EH, Weissman JS, Qi LS, et al. 2013. Dynamic imaging of genomic loci in living human cells by an optimized CRISPR/Cas system. Cell 155: 1479-1491. doi:10.1016/j.cell.2013.12.001

Chen C, Lim HH, Shi J, Tamura S, Maeshima K, Surana U, Gan L. 2016. Budding yeast chromatin is dispersed in a crowded nucleoplasm in vivo. Mol Biol Cell 27: $3357-$ 3368. doi:10.1091/mbc.E16-07-0506

Chen H, Levo M, Barinov L, Fujioka M, Jaynes JB, Gregor T. 2018. Dynamic interplay between enhancer-promoter topology and gene activity. Nat Genet 50: 1296-1303. doi:10 .1038/s41588-018-0175-z

Cho WK, Spille JH, Hecht M, Lee C, Li C, Grube V, Cisse II. 2018. Mediator and RNA polymerase II clusters associate in transcription-dependent condensates. Science 361: 412-415. doi:10.1126/science.aar4199

Chong S, Dugast-Darzacq C, Liu Z, Dong P, Dailey GM, Cattoglio C, Heckert A, Banala S, Lavis L, Darzacq X, et al. 2018. Imaging dynamic and selective low-complexity domain interactions that control gene transcription. Science 361: eaar2555. doi:10.1126/science.aar2555

Chubb JR, Boyle S, Perry P, Bickmore WA. 2002. Chromatin motion is constrained by association with nuclear compartments in human cells. Curr Biol 12: 439-445. doi:10 .1016/S0960-9822(02)00695-4

Church GM, Gao Y, Kosuri S. 2012. Next-generation digital information storage in DNA. Science 337: 1628. doi:10 $.1126 /$ science. 1226355

Cole A. 1967. Chromosome structure. Theoret Biophys 1: 305-375.

Collepardo-Guevara R, Schlick T. 2014. Chromatin fiber polymorphism triggered by variations of DNA linker lengths. Proc Natl Acad Sci 111: 8061-8066. doi:10 $.1073 /$ pnas.1315872111

Cook PR. 1999. The organization of replication and transcription. Science 284: 1790-1795. doi:10.1126/science .284 .5421 .1790

Cremer T, Cremer C. 2001. Chromosome territories, nuclear architecture and gene regulation in mammalian cells. Nat Rev Genet 2: 292-301. doi:10.1038/35066075

Davey CA, Sargent DF, Luger K, Maeder AW, Richmond TJ. 2002. Solvent mediated interactions in the structure of the nucleosome core particle at $1.9 \AA$ resolution. J Mol Biol 319: 1097-1113. doi:10.1016/S0022-2836(02)00386-8

Dekker J. 2008. Mapping in vivo chromatin interactions in yeast suggests an extended chromatin fiber with regional variation in compaction. J Biol Chem 283: 34532-34540. doi:10.1074/jbc.M806479200

* Dekker J. 2021. 3D chromatin organization. Cold Spring Harb Perspect Biol doi:10.1101/cshperspect.a040147

Dekker J, Heard E. 2015. Structural and functional diversity of topologically associating domains. FEBS Lett 589: 2877-2884. doi:10.1016/j.febslet.2015.08.044
Dion V, Gasser SM. 2013. Chromatin movement in the maintenance of genome stability. Cell 152: 1355-1364. doi:10.1016/j.cell.2013.02.010

Dion V, Kalck V, Seeber A, Schleker T, Gasser SM. 2013. Cohesin and the nucleolus constrain the mobility of spontaneous repair foci. EMBO Rep 14: 984-991. doi:10.1038/ embor.2013.142

Dixon JR, Selvaraj S, Yue F, Kim A, Li Y, Shen Y, Hu M, Liu JS, Ren B. 2012. Topological domains in mammalian genomes identified by analysis of chromatin interactions. Nature 485: 376-380. doi:10.1038/nature 11082

Dorigo B, Schalch T, Bystricky K, Richmond TJ. 2003. Chromatin fiber folding: requirement for the histone $\mathrm{H} 4$ N-terminal tail. J Mol Biol 327: 85-96. doi:10.1016/ S0022-2836(03)00025-1

Dubochet J, Adrian M, Schultz P, Oudet P. 1986. Cryo-electron microscopy of vitrified SV40 minichromosomes: the liquid drop model. EMBO J 5: 519-528. doi:10.1002/j $.1460-2075.1986 . t b 04241 . x$

Earnshaw WC, Laemmli UK. 1983. Architecture of metaphase chromosomes and chromosome scaffolds. J Cell Biol 96: 84-93. doi:10.1083/jcb.96.1.84

Edelman LB, Fraser P. 2012. Transcription factories: genetic programming in three dimensions. Curr Opin Genet Dev 22: 110-114. doi:10.1016/j.gde.2012.01.010

Eltsov M, Maclellan KM, Maeshima K, Frangakis AS, Dubochet J. 2008. Analysis of cryo-electron microscopy images does not support the existence of 30-nm chromatin fibers in mitotic chromosomes in situ. Proc Natl Acad Sci 105: 19732-19737. doi:10.1073/pnas.0810057105

Erdel F, Rademacher A, Vlijm R, Tunnermann J, Frank L, Weinmann R, Schweigert E, Yserentant K, Hummert J, Bauer C, et al. 2020. Mouse heterochromatin adopts digital compaction states without showing hallmarks of HP1-driven liquid-liquid phase separation. Mol Cell 78: 1236-249.e7.

Feuerborn A, Cook PR. 2015. Why the activity of a gene depends on its neighbors. Trends Genet 31: 483-490. doi:10.1016/j.tig.2015.07.001

Finch JT, Klug A. 1976. Solenoidal model for superstructure in chromatin. Proc Natl Acad Sci 73: 1897-1901. doi:10 $.1073 /$ pnas.73.6.1897

Fussner E, Strauss M, Djuric U, Li R, Ahmed K, Hart M, Ellis J, Bazett-Jones DP. 2012. Open and closed domains in the mouse genome are configured as $10-\mathrm{nm}$ chromatin fibres. EMBO Rep 13: 992-996. doi:10.1038/embor.2012.139

Germier T, Kocanova S, Walther N, Bancaud A, Shaban HA, Sellou H, Politi AZ, Ellenberg J, Gallardo F, Bystricky K. 2017. Real-time imaging of a single gene reveals transcription-initiated local confinement. Biophys J 113: 13831394. doi:10.1016/j.bpj.2017.08.014

Gibson BA, Doolittle LK, Schneider MWG, Jensen LE, Gamarra N, Henry L, Gerlich DW, Redding S, Rosen MK. 2019. Organization of chromatin by intrinsic and regulated phase separation. Cell 179: 470-484.e21. doi:10 $.1016 /$ j.cell.2019.08.037

Gómez-García PA, Portillo-Ledesma S, Neguembor MV, Pesaresi M, Oweis W, Rohrlich T, Wieser S, Meshorer E, Schlick T, Cosma MP, et al. 2021. Mesoscale modeling and single-nucleosome tracking reveal remodeling of clutch folding and dynamics in stem cell differentiation. Cell Rep 34: 108614. doi:10.1016/j.celrep.2020.108614 
K. Maeshima et al.

Gorisch SM, Wachsmuth M, Toth KF, Lichter P, Rippe K. 2005. Histone acetylation increases chromatin accessibility. J Cell Sci 118: 5825-5834. doi:10.1242/jcs.02689

Gu B, Swigut T, Spencley A, Bauer MR, Chung M, Meyer T, Wysocka J. 2018. Transcription-coupled changes in nuclear mobility of mammalian cis-regulatory elements. Science 359: 1050-1055. doi:10.1126/science.aao3136

Guo YE, Manteiga JC, Henninger JE, Sabari BR, Dall'Agnese A, Hannett NM, Spille JH, Afeyan LK, Zamudio AV, Shrinivas K, et al. 2019. Pol II phosphorylation regulates a switch between transcriptional and splicing condensates. Nature 572: 543-548. doi:10.1038/s41586-0191464-0

Hajjoul H, Mathon J, Ranchon H, Goiffon I, Mozziconacci J, Albert B, Carrivain P, Victor JM, Gadal O, Bystricky K, et al. 2013. High-throughput chromatin motion tracking in living yeast reveals the flexibility of the fiber throughout the genome. Genome Res 23: 1829-1838. doi:10.1101/gr .157008 .113

Hancock R. 2007. Packing of the polynucleosome chain in interphase chromosomes: evidence for a contribution of crowding and entropic forces. Semin Cell Dev Biol 18: 668-675. doi:10.1016/j.semcdb.2007.08.006

Hansen JC. 2002. Conformational dynamics of the chromatin fiber in solution: determinants, mechanisms, and functions. Annu Rev Biophys Biomol Struct 31: 361392. doi:10.1146/annurev.biophys.31.101101.140858

Hansen JC, Connolly M, McDonald CJ, Pan A, Pryamkova A, Ray K, Seidel E, Tamura S, Rogge R, Maeshima K. 2018. The 10-nm chromatin fiber and its relationship to interphase chromosome organization. Biochem Soc Trans 46: 67-76. doi:10.1042/BST20170101

Hendzel MJ, Boisvert F, Bazett-Jones DP. 1999. Direct visualization of a protein nuclear architecture. Mol Biol Cell 10: 2051-2062. doi:10.1091/mbc.10.6.2051

Heun P, Laroche T, Shimada K, Furrer P, Gasser SM. 2001. Chromosome dynamics in the yeast interphase nucleus. Science 294: 2181-2186. doi:10.1126/science.1065366

Hihara S, Pack CG, Kaizu K, Tani T, Hanafusa T, Nozaki T, Takemoto S, Yoshimi T, Yokota H, Imamoto N, et al. 2012. Local nucleosome dynamics facilitate chromatin accessibility in living mammalian cells. Cell Rep 2: 1645-1656. doi:10.1016/j.celrep.2012.11.008

Hoffman DP, Shtengel G, Xu CS, Campbell KR, Freeman M, Wang L, Milkie DE, Pasolli HA, Iyer N, Bogovic JA, et al. 2020. Correlative three-dimensional super-resolution and block-face electron microscopy of whole vitreously frozen cells. Science 367: eaaz5357. doi:10.1126/science.aaz5357

Hsieh TH, Weiner A, Lajoie B, Dekker J, Friedman N, Rando OJ. 2015. Mapping nucleosome resolution chromosome folding in yeast by micro-C. Cell 162: 108-119. doi:10 .1016/j.cell.2015.05.048

Hu Y, Kireev I, Plutz M, Ashourian N, Belmont AS. 2009. Large-scale chromatin structure of inducible genes: transcription on a condensed, linear template. J Cell Biol 185: 87-100. doi:10.1083/jcb.200809196

Hudson DF, Vagnarelli P, Gassmann R, Earnshaw WC. 2003. Condensin is required for nonhistone protein assembly and structural integrity of vertebrate mitotic chromosomes. Dev Cell 5: 323-336. doi:10.1016/S1534-5807 (03)00199-0
Hyman AA, Weber CA, Jülicher F. 2014. Liquid-liquid phase separation in biology. Ann Rev Cell Dev Biol 30: 39-58. doi:10.1146/annurev-cellbio-100913-013325

Ide S, Imai R, Ochi H, Maeshima K. 2020. Transcriptional suppression of ribosomal DNA with phase separation. $\mathrm{Sci}$ Adv 6: eabb5953. doi:10.1126/sciadv.abb5953

Imai R, Nozaki T, Tani T, Kaizu K, Hibino K, Ide S, Tamura S, Takahashi K, Shribak M, Maeshima K. 2017. Density imaging of heterochromatin in live cells using orientation-independent-DIC microscopy. Mol Biol Cell 28: 3349-3359. doi:10.1091/mbc.e17-06-0359

Itoh Y, Iida S, Tamura S, Nagashima R, Shiraki K, Goto T, Hibino K, Ide S, Maeshima K. 2021. 1,6-hexanediol rapidly immobilizes and condenses chromatin in living human cells. Life Sci Alliance 4: e202001005. doi:10.26508/ lsa.202001005

Joti Y, Hikima T, Nishino Y, Kamada F, Hihara S, Takata H, Ishikawa T, Maeshima K. 2012. Chromosomes without a 30-nm chromatin fiber. Nucleus 3: 404-410. doi:10.4161/ nucl.21222

Kan PY, Caterino TL, Hayes JJ. 2009. The H4 tail domain participates in intra- and internucleosome interactions with protein and DNA during folding and oligomerization of nucleosome arrays. Mol Cell Biol 29: 538-546. doi:10.1128/MCB.01343-08

* Khan J. 2021. Chromatin in cancer. Cold Spring Harb Perspect Biol doi:10.1101/cshperspect.a040956

Kieffer-Kwon KR, Nimura K, Rao SSP, Xu J, Jung S, Pekowska A, Dose M, Stevens E, Mathe E, Dong P, et al. 2017. Myc regulates chromatin decompaction and nuclear architecture during B cell activation. Mol Cell 67: 566-578. e10. doi:10.1016/j.molcel.2017.07.013

Kimura H, Cook PR. 2001. Kinetics of core histones in living human cells: little exchange of $\mathrm{H} 3$ and $\mathrm{H} 4$ and some rapid exchange of H2B. JCell Biol 153: 1341-1354. doi:10.1083/ jcb.153.7.1341

Kline AD, Moss JF, Selicorni A, Bisgaard AM, Deardorff MA, Gillett PM, Ishman SL, Kerr LM, Levin AV, Mulder PA, et al. 2018. Diagnosis and management of Cornelia de Lange syndrome: first international consensus statement. Nat Rev Genet 19: 649-666. doi:10.1038/s41576-0180031-0

Kornberg RD. 1974. Chromatin structure: a repeating unit of histones and DNA. Science 184: 868-871. doi:10.1126/ science.184.4139.868

Krietenstein N, Rando OJ. 2020. Mesoscale organization of the chromatin fiber. Curr Opin Genet Dev 61: 32-36. doi:10.1016/j.gde.2020.02.022

Larson AG, Elnatan D, Keenen MM, Trnka MJ, Johnston JB, Burlingame AL, Agard DA, Redding S, Narlikar GJ. 2017. Liquid droplet formation by HP1 $\alpha$ suggests a role for phase separation in heterochromatin. Nature 547: 236240. doi:10.1038/nature22822

Lerner J, Gomez-Garcia PA, McCarthy RL, Liu Z, Lakadamyali M, Zaret KS. 2020. Two-parameter mobility assessments discriminate diverse regulatory factor behaviors in chromatin. Mol Cell 79: 677-688.e6. doi:10.1016/j.molcel .2020 .05 .036

Levi V, Ruan Q, Plutz M, Belmont AS, Gratton E. 2005. Chromatin dynamics in interphase cells revealed by tracking in a two-photon excitation microscope. Biophys J 89: 4275-4285. doi:10.1529/biophysj.105.066670 
Lewis PW, Müller MM, Koletsky MS, Cordero F, Lin S, Banaszynski LA, Garcia BA, Muir TW, Becher OJ, Allis CD. 2013. Inhibition of PRC2 activity by a gain-of-function $\mathrm{H} 3$ mutation found in pediatric glioblastoma. Science 340: 857-861. doi:10.1126/science.1232245

Lieberman-Aiden E, van Berkum NL, Williams L, Imakaev M, Ragoczy T, Telling A, Amit I, Lajoie BR, Sabo PJ, Dorschner MO, et al. 2009. Comprehensive mapping of long-range interactions reveals folding principles of the human genome. Science 326: 289-293. doi:10.1126/sci ence. 1181369

Lin Y, Protter DS, Rosen MK, Parker R. 2015. Formation and maturation of phase-separated liquid droplets by RNA binding proteins. Mol Cell 60: 208-219. doi:10.1016/j .molcel.2015.08.018

Lu H, Yu D, Hansen AS, Ganguly S, Liu R, Heckert A, Darzacq X, Zhou Q. 2018. Phase-separation mechanism for C-terminal hyperphosphorylation of RNA polymerase II. Nature 558: 318-323. doi:10.1038/s41586-0180174-3

Luger K, Mäder AW, Richmond RK, Sargent DF, Richmond TJ. 1997. Crystal structure of the nucleosome core particle at $2.8 \AA$ resolution. Nature 389: 251-260. doi:10.1038/ 38444

Ma H, Tu LC, Chung YC, Naseri A, Grunwald D, Zhang S, Pederson T. 2019. Cell cycle- and genomic distance-dependent dynamics of a discrete chromosomal region. J Cell Biol 218: 1467-1477. doi:10.1083/jcb .201807162

Machida S, Takizawa Y, Ishimaru M, Sugita Y, Sekine S, Nakayama JI, Wolf M, Kurumizaka H. 2018. Structural basis of heterochromatin formation by human HP1. Mol Cell 69: 385-397.e8. doi:10.1016/j.molcel.2017.12.011

Maeshima K, Hihara S, Eltsov M. 2010. Chromatin structure: does the 30-nm fibre exist in vivo? Curr Opin Cell Biol 22: 291-297. doi:10.1016/j.ceb.2010.03.001

Maeshima K, Imai R, Tamura S, Nozaki T. 2014. Chromatin as dynamic 10-nm fibers. Chromosoma 123: 225-237. doi:10.1007/s00412-014-0460-2

Maeshima K, Kaizu K, Tamura S, Nozaki T, Kokubo T, Takahashi K. 2015. The physical size of transcription factors is key to transcriptional regulation in the chromatin domains. J Phys 27: 064116.

Maeshima K, Ide S, Hibino K, Sasai M. 2016a. Liquid-like behavior of chromatin. Curr Opin Genet Dev 37: 36-45. doi:10.1016/j.gde.2015.11.006

Maeshima K, Rogge R, Tamura S, Joti Y, Hikima T, Szerlong H, Krause C, Herman J, Seidel E, DeLuca J, et al. 2016b. Nucleosomal arrays self-assemble into supramolecular globular structures lacking 30-nm fibers. EMBO J 35: 1115-1132. doi:10.15252/embj.201592660

Maeshima K, Matsuda T, Shindo Y, Imamura H, Tamura S, Imai R, Kawakami S, Nagashima R, Soga T, Noji H, et al. 2018a. A transient rise in free $\mathrm{Mg}^{2+}$ ions released from ATP-Mg hydrolysis contributes to mitotic chromosome condensation. Curr Biol 28: 444-451.e6. doi:10.1016/j cub.2017.12.035

Maeshima K, Tamura S, Shimamoto Y. 2018b. Chromatin as a nuclear spring. Biophys Physicobiol 15: 189-195. doi:10 .2142/biophysico.15.0_189

Maeshima K, Tamura S, Hansen JC, Itoh Y. 2020. Fluid-like chromatin: toward understanding the real chromatin or- ganization present in the cell. Curr Opin Cell Biol 64: 7789. doi:10.1016/j.ceb.2020.02.016

Maison C, Quivy JP, Probst AV, Almouzni G. 2010. Heterochromatin at mouse pericentromeres: a model for de novo heterochromatin formation and duplication during replication. Cold Spring Harb Symp Quant Biol 75: 155-165. doi:10.1101/sqb.2010.75.013

Marenduzzo D, Finan K, Cook PR. 2006. The depletion attraction: an underappreciated force driving cellular organization. J Cell Biol 175: 681-686. doi:10.1083/jcb .200609066

Marshall WF, Straight A, Marko JF, Swedlow J, Dernburg A, Belmont A, Murray AW, Agard DA, Sedat JW. 1997. Interphase chromosomes undergo constrained diffusional motion in living cells. Curr Biol 7: 930-939. doi:10.1016/ S0960-9822(06)00412-X

McDowall AW, Smith JM, Dubochet J. 1986. Cryo-electron microscopy of vitrified chromosomes in situ. EMBO J 5: 1395-1402. doi:10.1002/j.1460-2075.1986.tb04373.x

Meister P, Towbin BD, Pike BL, Ponti A, Gasser SM. 2010. The spatial dynamics of tissue-specific promoters during C. elegans development. Genes Dev 24: 766-782. doi:10 $.1101 /$ gad. 559610

Meshorer E, Yellajoshula D, George E, Scambler PJ, Brown DT, Misteli T. 2006. Hyperdynamic plasticity of chromatin proteins in pluripotent embryonic stem cells. Dev Cell 10: 105-116. doi:10.1016/j.devcel.2005.10.017

Miron E, Oldenkamp R, Brown JM, Pinto DMS, Xu CS, Faria AR, Shaban HA, Rhodes JDP, Innocent C, de Ornellas S, et al. 2020. Chromatin arranges in chains of mesoscale domains with nanoscale functional topography independent of cohesin. Sci Adv 6: eaba8811. doi:10.1126/sciadv .aba8811

* Miroshnikova YA, Wickström SA. 2021. Mechanical forces in nuclear organization. Cold Spring Harb Perspect Biol doi:10.1101/cshperspect.a039685

Misteli T. 2010. Higher-order genome organization in human disease. Cold Spring Harb Perspect Biol 2: a000794. doi:10.1101/cshperspect.a000794

Misteli T. 2020. The self-organizing genome: principles of genome architecture and function. Cell 183: 28-45. doi: 10 $.1016 /$ j.cell.2020.09.014

Misteli T, Gunjan A, Hock R, Bustin M, Brown DT. 2000. Dynamic binding of histone $\mathrm{H} 1$ to chromatin in living cells. Nature 408: $877-881$. doi:10.1038/35048610

Mitrea DM, Kriwacki RW. 2016. Phase separation in biology; functional organization of a higher order. Cell Commun Signal 14: 1. doi:10.1186/s12964-015-0125-7

Morales C, Losada A. 2018. Establishing and dissolving cohesion during the vertebrate cell cycle. Curr Opin Cell Biol 52: 51-57. doi:10.1016/j.ceb.2018.01.010

Nacev BA, Feng L, Bagert JD, Lemiesz AE, Gao J, Soshnev AA, Kundra R, Schultz N, Muir TW, Allis CD. 2019. The expanding landscape of "oncohistone" mutations in human cancers. Nature 567: 473-478. doi:10.1038/s41586019-1038-1

Nagashima R, Hibino K, Ashwin SS, Babokhov M, Fujishiro S, Imai R, Nozaki T, Tamura S, Tani T, Kimura H, et al. 2019. Single nucleosome imaging reveals loose genome chromatin networks via active RNA polymerase II. J Cell Biol 218: 1511-1530. doi:10.1083/jcb.201811090 
K. Maeshima et al.

Nasmyth K, Haering CH. 2005. The structure and function of SMC and kleisin complexes. Annu Rev Biochem 74: 595-648. doi:10.1146/annurev.biochem.74 082803.133219

Nishino Y, Eltsov M, Joti Y, Ito K, Takata H, Takahashi Y, Hihara S, Frangakis AS, Imamoto N, Ishikawa T, et al. 2012. Human mitotic chromosomes consist predominantly of irregularly folded nucleosome fibres without a 30-nm chromatin structure. EMBO J 31: 1644-1653. doi:10.1038/emboj.2012.35

Nishiyama T. 2019. Cohesion and cohesin-dependent chromatin organization. Curr Opin Cell Biol 58: 8-14. doi:10 $.1016 /$ j.ceb.2018.11.006

Nora EP, Lajoie BR, Schulz EG, Giorgetti L, Okamoto I, Servant N, Piolot T, van Berlum NL, Meisig J, Sedat JW, et al.2012. Spatial partitioning of the regulatory landscape of the X-inactivation centre. Nature 485: 381-385. doi:10 $.1038 /$ nature11049

Nozaki T, Imai R, Tanbo M, Nagashima R, Tamura S, Tani T, Joti Y, Tomita M, Hibino K, Kanemaki MT, et al. 2017. Dynamic organization of chromatin domains revealed by super-resolution live-cell imaging. Mol Cell 67: 282-293. e7. doi:10.1016/j.molcel.2017.06.018

Nozaki T, Hudson DF, Tamura S, Maeshima K. 2018. Dynamic chromatin folding in the cell. In Nuclear architecture and dynamics (ed. C Lavelle, JM Victor), pp. 101122. Academic, New York.

Nozawa RS, Gilbert N. 2019. RNA: nuclear glue for folding the genome. Trends Cell Biol 29: 201-211. doi:10.1016/j .tcb.2018.12.003

Nozawa RS, Boteva L, Soares DC, Naughton C, Dun AR, Buckle A, Ramsahoye B, Bruton PC, Saleeb RS, Arnedo $\mathrm{M}$, et al. 2017. SAF-A regulates interphase chromosome structure through oligomerization with chromatin-associated RNAs. Cell 169: 1214-1227.e18. doi:10.1016/j.cell 2017.05.029

Ohno M, Ando T, Priest DG, Kumar V, Yoshida Y, Taniguchi Y. 2019. Sub-nucleosomal genome structure reveals distinct nucleosome folding motifs. Cell 176: 520-534. e25. doi:10.1016/j.cell.2018.12.014

Olins AL, Olins DE. 1974. Spheroid chromatin units (v bodies). Science 183: 330-332. doi:10.1126/science .183 .4122 .330

Olins DE, Olins AL. 2003. Chromatin history: our view from the bridge. Nat Rev Mol Cell Biol 4: 809-814. doi:10.1038/ nrm 1225

Olins DE, Olins AL. 2018. Epichromatin and chromomeres: a "fuzzy" perspective. Open Biol 8: 180058. doi:10.1098/ rsob. 180058

Ou HD, Phan S, Deerinck TJ, Thor A, Ellisman MH, O'Shea CC. 2017. ChromEMT: visualizing 3D chromatin structure and compaction in interphase and mitotic cells. Science 357: eaag0025. doi:10.1126/science.aag0025

* Pawar S, Kutay U. 2021. The diverse cellular functions of inner nuclear membrane proteins. Cold Spring Harb Perspect Biol doi:10.1101/cshperspect.a040477.

Pecqueur C, Oliver L, Oizel K, Lalier L, Vallette FM. 2013. Targeting metabolism to induce cell death in cancer cells and cancer stem cells. Int J Cell Biol 2013: 805975. doi:10 $.1155 / 2013 / 805975$
Pepenella S, Murphy KJ, Hayes JJ. 2014a. Intra- and internucleosome interactions of the core histone tail domains in higher-order chromatin structure. Chromosoma 123: 3-13. doi:10.1007/s00412-013-0435-8

Pepenella S, Murphy KJ, Hayes JJ. 2014b. A distinct switch in interactions of the histone $\mathrm{H} 4$ tail domain upon salt-dependent folding of nucleosome arrays. J Biol Chem 289: 27342-27351. doi:10.1074/jbc.M114.595140

Qian Y, Wang X, Liu Y, Li Y, Colvin RA, Tong L, Wu S, Chen X. 2014. Extracellular ATP is internalized by macropinocytosis and induces intracellular ATP increase and drug resistance in cancer cells. Cancer Lett 351: 242-251. doi:10.1016/j.canlet.2014.06.008

Rao SS, Huntley MH, Durand NC, Stamenova EK, Bochkov ID, Robinson JT, Sanborn AL, Machol I, Omer AD, Lander ES, et al. 2014. A 3D map of the human genome at kilobase resolution reveals principles of chromatin looping. Cell 159: 1665-1680. doi:10.1016/j.cell.2014.11 .021

Rao SSP, Huang SC, Glenn St Hilaire B, Engreitz JM, Perez EM, Kieffer-Kwon KR, Sanborn AL, Johnstone SE, Bascom GD, Bochkov ID, et al. 2017. Cohesin loss eliminates all loop domains. Cell 171: 305-320.e24. doi:10.1016/j cell.2017.09.026

* Reddy K. 2021. Nuclear lamina. Cold Spring Harb Perspect Biol doi:10.1101/cshperspect.a040113.

Ricci MA, Manzo C, García-Parajo MF, Lakadamyali M, Cosma MP. 2015. Chromatin fibers are formed by heterogeneous groups of nucleosomes in vivo. Cell 160: 11451158. doi:10.1016/j.cell.2015.01.054

* Rippe K. 2021. Phase separation in chromatin. Cold Spring Harb Perspect Biol doi:10.1101/cshperspect.a040683

Risca VI, Denny SK, Straight AF, Greenleaf WJ. 2017. Variable chromatin structure revealed by in situ spatially correlated DNA cleavage mapping. Nature 541: 237-241. doi:10.1038/nature20781

Robinett CC, Straight A, Li G, Willhelm C, Sudlow G, Murray A, Belmont AS. 1996. In vivo localization of DNA sequences and visualization of large-scale chromatin organization using lac operator/repressor recognition. J Cell Biol 135: 1685-1700. doi:10.1083/jcb.135 6.1685

Robinson PJ, Fairall L, Huynh VA, Rhodes D. 2006. EM measurements define the dimensions of the "30-nm" chromatin fiber: evidence for a compact, interdigitated structure. Proc Natl Acad Sci 103: 6506-6511. doi:10 $.1073 /$ pnas.0601212103

Sabari BR, Dall'Agnese A, Boija A, Klein IA, Coffey EL, Shrinivas K, Abraham BJ, Hannett NM, Zamudio AV, Manteiga JC, et al. 2018. Coactivator condensation at super-enhancers links phase separation and gene control. Science 361: eaar3958. doi:10.1126/science .aar3958

Sanborn AL, Rao SS, Huang SC, Durand NC, Huntley MH, Jewett AI, Bochkov ID, Chinnappan D, Cutkosky A, Li J, et al. 2015. Chromatin extrusion explains key features of loop and domain formation in wild-type and engineered genomes. Proc Natl Acad Sci 112: E6456-E6465. doi:10 $.1073 /$ pnas. 1518552112

Sanulli S, Trnka MJ, Dharmarajan V, Tibble RW, Pascal BD, Burlingame AL, Griffin PR, Gross JD, Narlikar GJ. 2019. HP1 reshapes nucleosome core to promote phase separa- 
tion of heterochromatin. Nature 575: 390-394. doi:10 .1038/s41586-019-1669-2

Schalch T, Duda S, Sargent DF, Richmond TJ. 2005. X-ray structure of a tetranucleosome and its implications for the chromatin fibre. Nature 436: 138-141. doi:10.1038/na ture 03686

Schwartzentruber J, Korshunov A, Liu XY, Jones DT, Pfaff E, Jacob K, Sturm D, Fontebasso AM, Quang DA, Tönjes M et al. 2012. Driver mutations in histone H3.3 and chromatin remodelling genes in paediatric glioblastoma. $\mathrm{Na}$ ture 482: 226-231. doi:10.1038/nature10833

Seeber A, Hauer MH, Gasser SM. 2018. Chromosome dynamics in response to DNA damage. Annu Rev Genet 52: 295-319. doi:10.1146/annurev-genet-120417-031334

Sexton T, Yaffe E, Kenigsberg E, Bantignies F, Leblanc B, Hoichman M, Parrinello H, Tanay A, Cavalli G. 2012. Three-dimensional folding and functional organization principles of the Drosophila genome. Cell 148: 458-472. doi:10.1016/j.cell.2012.01.010

Shaban HA, Barth R, Recoules L, Bystricky K. 2020. Hi-D: nanoscale mapping of nuclear dynamics in single living cells. Genome Biol 21: 95. doi:10.1186/s13059-02002002-6

Shimamoto Y, Tamura S, Masumoto H, Maeshima K. 2017. Nucleosome-nucleosome interactions via histone tails and linker DNA regulate nuclear rigidity. Mol Biol Cell 28: 1580-1589. doi:10.1091/mbc.e16-11-0783

Shinkai S, Nozaki T, Maeshima K, Togashi Y. 2016. Dynamic nucleosome movement provides structural information of topological chromatin domains in living human cells. PLoS Comput Biol 12: e1005136. doi:10.1371/journal .pcbi.1005136

Sinha D, Shogren-Knaak MA. 2010. Role of direct interactions between the histone $\mathrm{H} 4$ tail and the $\mathrm{H} 2 \mathrm{~A}$ core in long range nucleosome contacts. J Biol Chem 285: 16572 16581. doi:10.1074/jbc.M109.091298

Song F, Chen P, Sun D, Wang M, Dong L, Liang D, Xu RM, Zhu P, Li G. 2014. Cryo-EM study of the chromatin fiber reveals a double helix twisted by tetranucleosomal units. Science 344: 376-380. doi:10.1126/science.1251413

Soutoglou E, Misteli T. 2007. Mobility and immobility of chromatin in transcription and genome stability. Curr Opin Genet Dev 17: 435-442. doi:10.1016/j.gde.2007.08 .004

Stephens AD, Banigan EJ, Adam SA, Goldman RD, Marko JF. 2017. Chromatin and lamin A determine two different mechanical response regimes of the cell nucleus. Mol Biol Cell.

Strickfaden H, Tolsma TO, Sharma A, Underhill DA, Hansen JC, Hendzel MJ. 2020. Condensed chromatin behaves like a solid on the mesoscale in vitro and in living cells. Cell 183: 1772-1784.e13. doi:10.1016/j.cell.2020.11.027

Strom AR, Emelyanov AV, Mir M, Fyodorov DV, Darzacq X, Karpen GH. 2017. Phase separation drives heterochromatin domain formation. Nature 547: 241-245. doi:10.1038/ nature22989

Takata H, Hanafusa T, Mori T, Shimura M, Iida Y, Ishikawa K, Yoshikawa K, Yoshikawa Y, Maeshima K. 2013. Chromatin compaction protects genomic DNA from radiation damage. PLoS ONE 8: e75622. doi:10.1371/journal.pone .0075622
Tasan I, Sustackova G, Zhang L, Kim J, Sivaguru M, HamediRad M, Wang Y, Genova J, Ma J, Belmont AS, et al. 2018. CRISPR/Cas9-mediated knock-in of an optimized TetO repeat for live cell imaging of endogenous loci. Nucleic Acids Res 46: e100. doi:10.1093/nar/ gky501

Toth KF, Knoch TA, Wachsmuth M, Frank-Stohr M, Stohr M, Bacher CP, Muller G, Rippe K. 2004. Trichostatin Ainduced histone acetylation causes decondensation of interphase chromatin. J Cell Sci 117: 4277-4287. doi:10 $.1242 /$ jcs. 01293

Turner AL, Watson M, Wilkins OG, Cato L, Travers A, Thomas JO, Stott K. 2018. Highly disordered histone H1-DNA model complexes and their condensates. Proc Natl Acad Sci 115: 11964-11969. doi:10.1073/pnas .1805943115

van Steensel B, Belmont AS. 2017. Lamina-associated domains: links with chromosome architecture, heterochromatin, and gene repression. Cell 169: 780-791. doi:10 .1016/j.cell.2017.04.022

Visvanathan A, Ahmed K, Even-Faitelson L, Lleres D, Bazett-Jones DP, Lamond AI. 2013. Modulation of higher order chromatin conformation in mammalian cell nuclei can be mediated by polyamines and divalent cations. PLoS ONE 8: e67689. doi:10.1371/journal.pone .0067689

Wolffe AP, Hayes JJ. 1999. Chromatin disruption and modification. Nucleic Acids Res 27: 711-720. doi:10.1093/nar/ 27.3.711

Woodcock CL, Safer JP, Stanchfield JE. 1976. Structural repeating units in chromatin. I: Evidence for their general occurrence. Exp Cell Res 97: 101-110. doi:10.1016/00144827(76)90659-5

Woodcock CL, Frado LL, Rattner JB. 1984. The higherorder structure of chromatin: evidence for a helical ribbon arrangement. J Cell Biol 99: 42-52. doi:10.1083/ jcb.99.1.42

Woodcock CL, Skoultchi AI, Fan Y. 2006. Role of linker histone in chromatin structure and function: $\mathrm{H} 1$ stoichiometry and nucleosome repeat length. Chromosome Res 14: 17-25. doi:10.1007/s10577-005-1024-3

Wu G, Broniscer A, McEachron TA, Lu C, Paugh BS, Becksfort J, Qu C, Ding L, Huether R, Parker M, et al. 2012. Somatic histone H3 alterations in pediatric diffuse intrinsic pontine gliomas and non-brainstem glioblastomas. Nat Genet 44: 251-253. doi:10.1038/ng .1102

Wutz G, Várnai C, Nagasaka K, Cisneros DA, Stocsits RR, Tang W, Schoenfelder S, Jessberger G, Muhar M, Hossain MJ, et al. 2017. Topologically associating domains and chromatin loops depend on cohesin and are regulated by CTCF, WAPL, and PDS5 proteins. EMBO $J$ 36: 3573-3599. doi:10.15252/embj.201798004

Xu J, Ma H, Jin J, Uttam S, Fu R, Huang Y, Liu Y. 2018. Super-resolution imaging of higher-order chromatin structures at different epigenomic states in single mammalian cells. Cell Rep 24: 873-882. doi:10.1016/j.celrep .2018 .06 .085

Yusufova N, Kloetgen A, Teater M, Osunsade A, Camarillo JM, Chin CR, Doane AS, Venters BJ, Portillo-Ledesma S, Conway J, et al. 2021. Histone H1 loss drives lymphoma 
K. Maeshima et al.

by disrupting 3D chromatin architecture. Nature 589: 299-305. doi:10.1038/s41586-020-3017-y

Zheng C, Lu X, Hansen JC, Hayes JJ. 2005. Salt-dependent intra- and internucleosomal interactions of the $\mathrm{H} 3$ tail domain in a model oligonucleosomal array. J Biol Chem 280: 33552-33557. doi:10.1074/jbc.M507241200

Zidovska A, Weitz DA, Mitchison TJ. 2013. Micron-scale coherence in interphase chromatin dynamics. Proc
Natl Acad Sci 110: 15555-15560. doi:10.1073/pnas .1220313110

Zuin J, Dixon JR, van der Reijden MIJA, Ye Z, Kolovos P, Brouwer RWW, van de Corput MPC, van de Werken HJG, Knoch TA, van IJcken WFJ, et al. 2014. Cohesin and CTCF differentially affect chromatin architecture and gene expression in human cells. Proc Natl Acad Sci 111: 996-1001. doi:10.1073/pnas.1317788111 


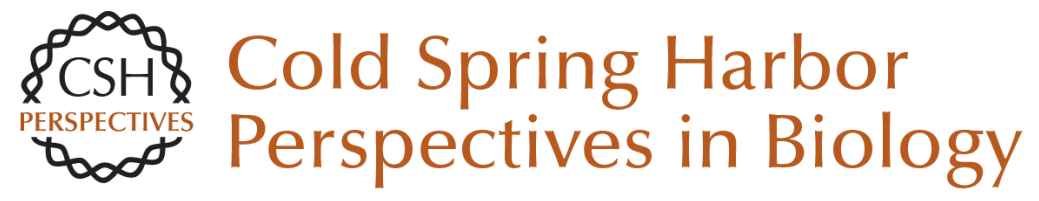

\section{Physical Nature of Chromatin in the Nucleus}

Kazuhiro Maeshima, Shiori lida and Sachiko Tamura

Cold Spring Harb Perspect Biol 2021; doi: 10.1101/cshperspect.a040675 originally published online April 5,2021

\section{Subject Collection The Nucleus}

Nuclear Compartments: An Incomplete Primer to Nuclear Compartments, Bodies, and Genome Organization Relative to Nuclear Architecture Andrew S. Belmont

Uncovering the Principles of Genome Folding by 3D Chromatin Modeling

Asli Yildirim, Lorenzo Boninsegna, Yuxiang Zhan, et al.

3D or Not 3D: Shaping the Genome during Development Juliane Glaser and Stefan Mundlos

The Impact of Space and Time on the Functional Output of the Genome Marcelo Nollmann, Isma Bennabi, Markus Götz, et al.

Chromatin Mechanisms Driving Cancer

Berkley Gryder, Peter C. Scacheri, Thomas Ried, et al.

Liquid-Liquid Phase Separation in Chromatin Karsten Rippe

Mechanical Forces in Nuclear Organization Yekaterina A. Miroshnikova and Sara A. Wickström

Imaging Organization of RNA Processing within the Nucleus

Jeetayu Biswas, Weihan Li, Robert H. Singer, et al.
Mechanisms of Chromosome Folding and Nuclear Organization: Their Interplay and Open Questions Leonid Mirny and Job Dekker

Epigenetic Reprogramming in Early Animal Development

Zhenhai Du, Ke Zhang and Wei Xie

Essential Roles for RNA in Shaping Nuclear Organization

Sofia A. Quinodoz and Mitchell Guttman

The Molecular and Nuclear Dynamics of

$\mathrm{X}$-Chromosome Inactivation

François Dossin and Edith Heard

Structure, Maintenance, and Regulation of

Nuclear Pore Complexes: The Gatekeepers of the

Eukaryotic Genome Marcela Raices and Maximiliano A. D'Angelo

The Nuclear Lamina Xianrong Wong, Ashley J. Melendez-Perez and Karen L. Reddy

The Nuclear Pore Complex as a Transcription Regulator Michael Chas Sumner and Jason Brickner

Physical Nature of Chromatin in the Nucleus Kazuhiro Maeshima, Shiori lida and Sachiko Tamura

For additional articles in this collection, see http://cshperspectives.cshlp.org/cgi/collection/

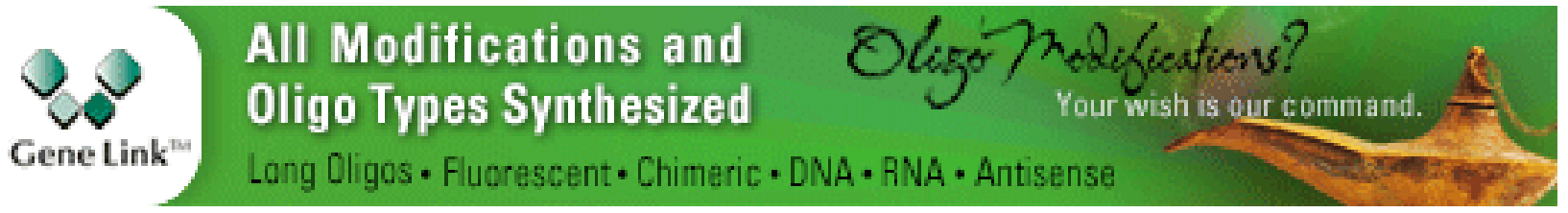

Copyright @ 2021 Cold Spring Harbor Laboratory Press; all rights reserved 
For additional articles in this collection, see http://cshperspectives.cshlp.org/cgi/collection/

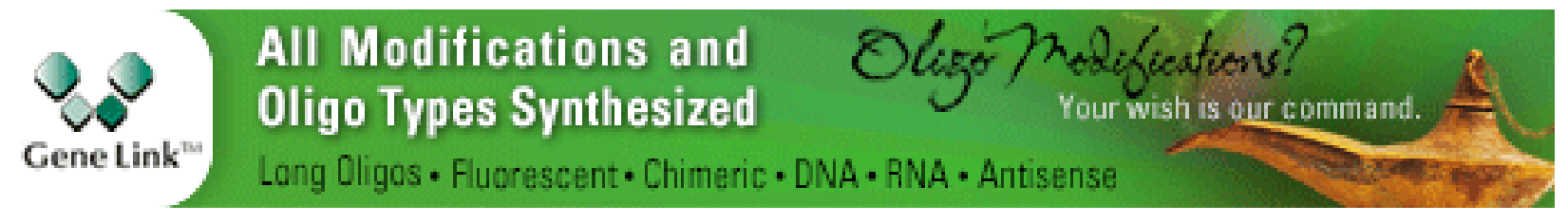

Copyright @ 2021 Cold Spring Harbor Laboratory Press; all rights reserved 